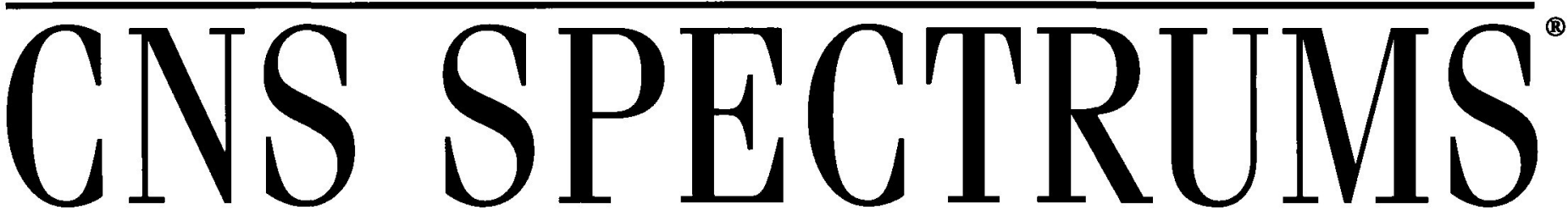

The International Journal of Neuropsychiatric Medicine

\title{
2
}

\section{Novel Pharmacotherapies for Alcoholism}

\section{Clinical Management of Alcohol Withdrawal}

\author{
H. Myrick and R. F. Anton
}

Role of Serotonin and Serotonin-Selective

Pharmacotherapy in Alcohol Dependence

H.M. Pettinati, D. Oslin, and K. Decker

Opioid Antagonists and Alcoholism Treatment

R.M. Swift

Acamprosate for the Treatment of Alcohol Dependence:

A Review of Double-Blind, Placebo-Controlled Trials

B. Mason and R. L. Ownby

Combination Pharmacotherapy in Alcoholism:

A Novel Treatment Approach

C. K. Farren, A. H. Rezvani, D. Overstreet, and S. O'Malley 


\section{More physicians are diagnosing Alzheimer's disease.}

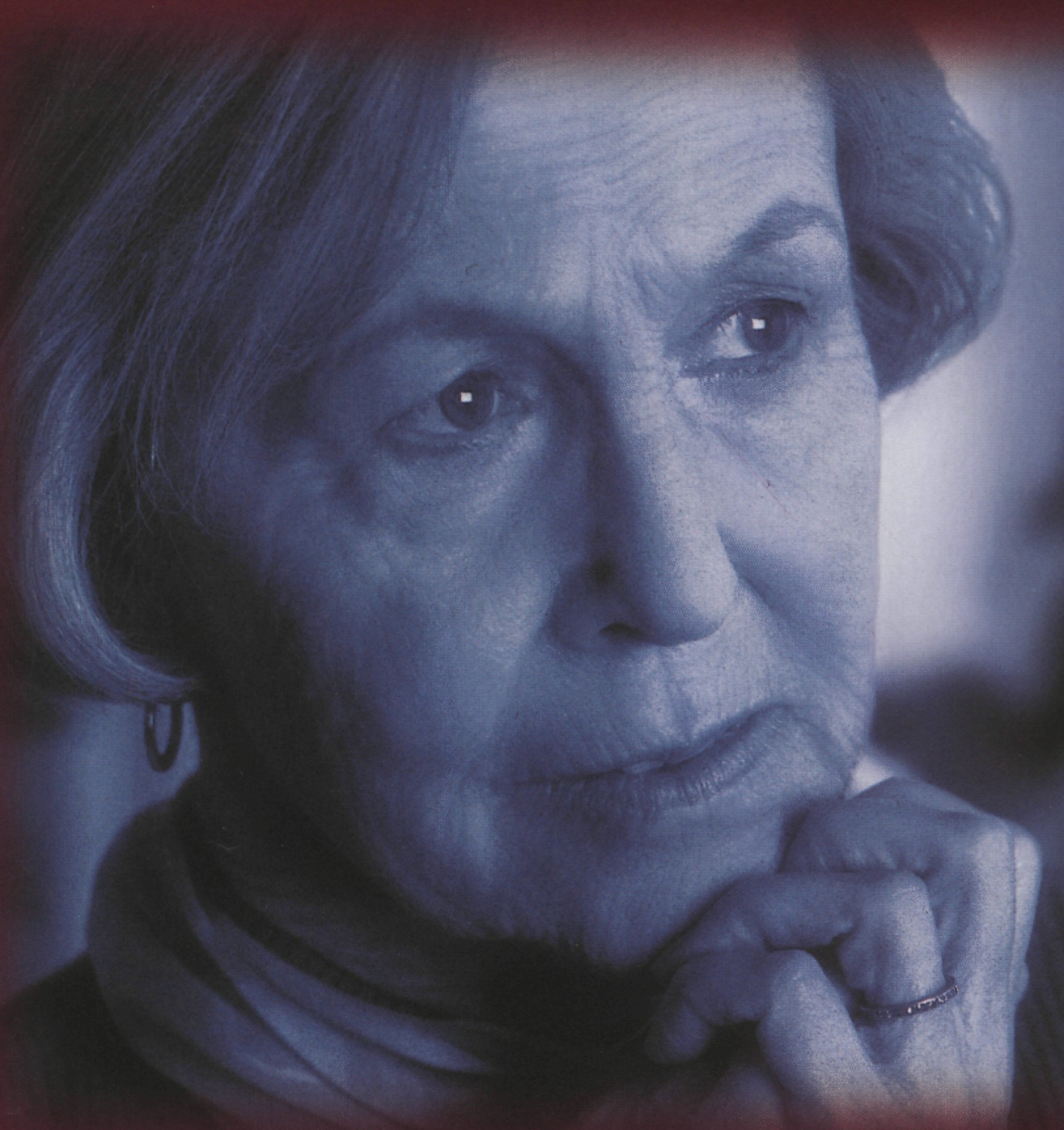

"The most common adverse events leading to discontinuation in clinical trials with ARICEPT ${ }^{\oplus}$ (donepezil HCl) were nausea, diarrhea, and vomiting. Clinical studies of ARICEPT ${ }^{\oplus}$ have shown no increase, relative to placebo, in the incidence of either peptic ulcer disease or gastrointestinal bleeding. Nevertheless, cholinesterase inhibitors may be expected to increase gastric acid secretion. Therefore, patients (especially those at increased risk for developing ulcers - eg, history of ulcer disease, receiving concurrent nonsteroidal anti-inflammatory drugs) should be monitored closely for gastrointestinal bleeding. In clinical trials, syncopal episodes have been reported in association with the use of ARICEPT ${ }^{\oplus}$ (2\% vs $1 \%$ for placebo). 


\section{That's why they're prescribing ARICEPT $^{\oplus}$ (donepezil HCl)}

\section{Clinically Proven to Enhance Cognitive Function}

With over 700,000 patient starts, ARICEPT $^{\oplus}$ is the world's most-prescribed therapy for the treatment of mild to moderate Alzheimer's disease. Remember ARICEPT ${ }^{\oplus}$ for these important benefits:

- Once-daily dosing

- No titration required

- Excellent safety profile

-Well-tolerated therapy*

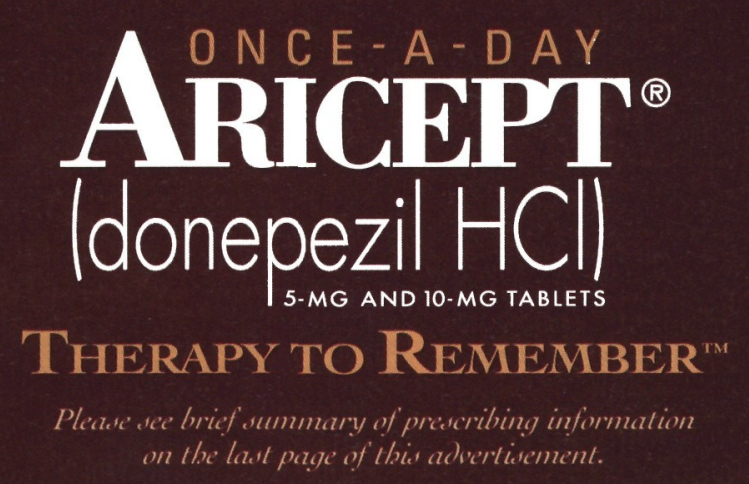




\section{A}

THERAPY TO REMEMBER

ARICEPT ${ }^{\circ}$ (Donepezil Hydrochloride Tablets)

Brief Summary - see package insert for full prescribing information. INDICATIONS AND USAGE ARICEPT ${ }^{\circledR}$ is indicate for the treatment of mild to moderate dementia of the Alzheimer's type. CONTRAINDICATIONS ARICEPT is WARNINGS Anesthesia: ARICEPT as a cholinesterase inhibitor, is likely to exaggerate succinylcholine-type muscl relaxation during anesthesia. Cardiovascular Conditions: Because of their pharmacological action, cholinesterase inhibitors may have vagotonic effects on heart rate (eg, bradycardia). The potential for this action may be particularly inhortant to patients with "sick sinus on heart rate (eg, bradycardia). The potential for this action may be particularly important to patients with "sick sinus syndrome" or other supraventricular cardiac conduction conditions. Syncopal
episodes have been reported in association with the use of ARICEPT . Gastrointestinal Conditions: Through their primary action, cholinesterase inhibitors may be expected to increase gastric acid secretion due to increased cholinergic primary action, cholinesterase inhibitors may be expected to increase gastric acid secretion due to increased cholinergic activity. Therefore, patients should be monitored closely for symptoms of active or occult gastrointestinal bleeding,
especially those at increased risk for developing ulcers, eg, those with a history of ulcer disease or those receiving concurrent nonsteroidal anti-inflammatory drugs (NSAIDS). Clinical studies of ARICEPT ${ }^{\circ}$ have shown no increase, relative to placebo, in the incidence of either peptic ulcer disease or gastrointestinal bleeding. ARICEPT ${ }^{\circledR}$, as a predictable consequence of its pharmacological properties, has been shown to produce diarrhea nausea and vomiting. These effects, when they occur, appear more frequently with the $10 \mathrm{mg} / \mathrm{day}$ dose than with the $5 \mathrm{mg} / \mathrm{day}$ dose. In most cases, these effects have been mild and transient, sometimes lasting one to three weeks, and have resolved during continued use of ARICEPT Genitourinary: Although not observed in clinical trials of ARICEPT', cholinomimetics may cause bladder outflow
obstruction. Neurological Conditions: Seizures: Cholinomimetics are believed to have some potential to caus obstruction. Neurological Conditions: Seizures: Cholinomimetics are believed to have some potential to cause Conditions: Because of their cholinomimetic actions, cholinesterase inhibitors should be prescribed with care to patien with a history of asthma or obstructive pulmonary disease. PRECAUTIONS Drug-Drug Interactions Drugs Highly Bound to Plasma Proteins: Drug displacement studies have been performed in vitro between this highly bound drug $(96 \%)$ and other drugs such as furosemide, digoxin, and warfarin. ARICEPT ${ }^{\circledR}$ at concentrations of $0.3-10 \mu \mathrm{g} / \mathrm{mL}$ did no affect the binding of furosemide $(5 \mu \mathrm{g} / \mathrm{mL})$, digoxin $(2 \mathrm{ng} / \mathrm{mL})$, and warfarin $(3 \mu \mathrm{g} / \mathrm{mL})$ to human albumin. Similarly, the the Metabolism of Other Drugs: No in vivo clinical trials have investigated the effect of ARICEPT ${ }^{\circledR}$ on the clearance drugs metabo lized by CYP $3 A 4$ (eg, cisapride, terfenadine) or by CYP $2 D 6$ (eg, imipramine). However, in vitro studies
show a low rate of binding to these enzymes (mean $K_{i}$ about $50-130 \mu \mathrm{M}$ ), that, given the therapeutic plasma concentrations of donepezil ( $164 \mathrm{nM}$ ), indicates little likelihood of interference. Whether ARICEPT ${ }^{\circledR}$ has any potential for enzyme induction is not known. Formal pharmacokinetic studies evaluated the potential of ARICEPT ${ }^{\oplus}$ for interaction with theophylline, cimetidine, warfarin and digoxin. No significant effects on the pharmacokinetics of these drugs were observed. Effect of Other Drugs on the Metabolism of ARICEPT: Ketoconazole and quinidine, inhibitors o CYP450, 3A4 and 2D6, respectively, inhibit donepezil metabolism in vitro. Whether there is a clinical effect of thes inhibitors is not known. Inducers of CYP $2 D 6$ and CYP 3 A4 (eg. phenytoin, carbamazepine, dexamethasone, rifampin, an phenobarbital) could increase the rate of elimination of ARICEPT ${ }^{\oplus}$. Formal pharmacokinetic studies demonstrated that the metabolism of ARICEPT is not significantly affected by concurrent administration of digoxin or cimetidine. Use with activity of anticholinergic medications. Use with Cholinomimetics and Other Cholinesterase Inhibitors: A synergistic effect may be expected when cholinesterase inhibitors are given concurrently with succinylcholine simila synergistic effect may be expected when cholinesterase inhibitors are given concurrently with succinylcholine, similar neuromuscular blocking agents or cholinergic agonists such as bethanechol. Carcinogenesis, Mutagenesis, Impairment of Fertility Carcinogenicity studies of donepezil have not been completed. Donepezil was not mutagenic in
the Ames reverse mutation assay in bacteria. In the chromosome aberration test in cultures of Chinese hamster lung (CHL) cells, some clastogenic effects were observed. Donepezil was not clastogenic in the in vivo mouse micronucleus test Donepezil had no effect on fertility in rats at doses up to $10 \mathrm{mg} / \mathrm{kg} / \mathrm{day}$ (approximately 8 times the maximum recommended human dose on a mg/m² basis). Pregnancy Pregnancy Category $\mathrm{C}$ : Teratology studies conducted in pregnant rats a oses up to $16 \mathrm{mg} / \mathrm{kg} / \mathrm{day}$ (approximately 13 times the maximum recommended human dose on a $\mathrm{mg} / \mathrm{m}^{2}$ basis) and in

\begin{tabular}{|c|c|c|c|c|}
\hline \multicolumn{5}{|c|}{$\begin{array}{l}\text { Table 1. Comparison of Rates of Adverse Events in Patients } \\
\text { Titrated to } 10 \mathrm{mg} / \text { day Over } 1 \text { and } 6 \text { Weeks }\end{array}$} \\
\hline \multirow[b]{2}{*}{ Adverse Event } & \multicolumn{2}{|c|}{ No titration } & \multirow{2}{*}{$\begin{array}{c}\begin{array}{c}\text { One-week } \\
\text { titration }\end{array} \\
10 \mathrm{mg} / \text { day } \\
(\mathrm{n}=315)\end{array}$} & \multirow{2}{*}{$\begin{array}{c}\begin{array}{c}\text { Six-week } \\
\text { titration }\end{array} \\
10 \mathrm{mg} / \text { day } \\
(\mathrm{n}=269)\end{array}$} \\
\hline & $\begin{array}{l}\text { Placebo } \\
(n=315)\end{array}$ & $\begin{array}{c}5 \mathrm{mg} / \text { day } \\
(\mathrm{n}=311)\end{array}$ & & \\
\hline Nausea & $6 \%$ & $5 \%$ & $19 \%$ & $6 \%$ \\
\hline Diarrhea & $5 \%$ & $8 \%$ & $15 \%$ & $9 \%$ \\
\hline Insomnia & $6 \%$ & $6 \%$ & $14 \%$ & $6 \%$ \\
\hline Fatigue & $3 \%$ & $4 \%$ & $8 \%$ & $3 \%$ \\
\hline Vomiting & $3 \%$ & $3 \%$ & $8 \%$ & $5 \%$ \\
\hline Muscle Cramps & $2 \%$ & $6 \%$ & $8 \%$ & $3 \%$ \\
\hline Anorexia & $2 \%$ & $3 \%$ & $7 \%$ & $3 \%$ \\
\hline
\end{tabular}

pregnant rabbits at doses up to $10 \mathrm{mg} / \mathrm{kg} /$ day (approximately 16 times the maximum recommended human dose on lats were gis) did not disclose any evidence for a teratogenic potential of donepezil. However, in a study in which pregnan from day 17 of gestation through day 20 postpartum, there was a slight increase in still births and a slight decrease in pup survival through day 4 postpartum at this dose; the next lower dose tested was $3 \mathrm{mg} / \mathrm{kg} /$ day. There are no adequate or wellcontrolled studies in pregnant women. ARICEPT ${ }^{\circledR}$ should be used during pregnancy only if the potential benefit justifies the potential risk to the fetus. Nursing Mothers It is not known whether donepezil is excreted in human breast milk. potential risk to the fetus. Nursing Mothers It is not known whether donepezil is excreted in human breast milk.
ARICEPT ARICEPT has no indication for use in nursing mothers. Pediatric Use There are no adequate and well-controlled trials to
document the safety and efficacy of ARICEPT in any illness occurring in children. ADVERSE REACTIONS Adverse Events Leading to Discontinuation The rates of discontinuation from controlled clinical trials of ARICEPT ${ }^{\otimes}$ due to adverse events for the ARICEPT ${ }^{\circledast 5 \mathrm{mg}}$ /day treatment groups were comparable to those of placebo-treatment groups a approximately $5 \%$. The rate of discontinuation of patients who received 7-day escalations from $5 \mathrm{mg} / \mathrm{day}$ to $10 \mathrm{mg} / \mathrm{day}$, was higher at $13 \%$. The most common adverse events leading to discontinuation, defined as those occurring in at least $2 \%$ of patients and at twice the incidence seen in placebo patients were nausea ( $1 \%[5 \mathrm{mg}]$ and $3 \%$ [10 $\mathrm{mg}]$ vs $1 \%$ Iplacebo]), diarrhea (<1\% [5 mg] and 3\% [10 mg] vs 0\% [placebo]), and vomiting ( $<1 \%[5 \mathrm{mg}]$ and $2 \%$ [10 $\mathrm{mg}$ vs $<1 \%$ [placebo]). Most Frequent Adverse Clinical Events Seen in Association with the Use of ARICEPT The most common adverse events, defined as those occurring at a frequency of at least $5 \%$ in patients receiving $10 \mathrm{mg} /$ day and twice the placebo rate, are largely predicted by ARICEPT''s cholinomimetic effects. These include nausea, diarrhea, insomnia, vomiting, muscle cramp, fatigue, and anorexia. These adverse events were often of mild intensity and transient, resolving during continued ARICEPT treatment without the need for dose modification. There is evidence to suggest that the frequency of these common adverse events may be affected by the rate of titration. An openlabel study was conducted with 269 patients who received placebo in the 15- and 30-week studies. These patients were titrated to a dose of $10 \mathrm{mg} /$ day over a 6 -week period. The rates of common adverse events were lower than those seen in patients titrated to $10 \mathrm{mg} /$ day over one week in the controlled clinical trials and were comparable to those seen in patients on $5 \mathrm{mg} /$ day. See Table 1 for a comparison of the most common adverse events following one week and six week titration regimens. Adverse Events Reported in Controlled Trials The events cited reflect experience gained under closely monitored conditions of clinical trials in a highly selected patient population. In actual clinical practice or in other clinical trials, these frequency estimates may not apply, as the conditions of use, reporting behavior, and the kinds of patients trials, these frequency estimates may not apply, as the conditions of use, reporting behavior, and the kinds of patients
treated may differ. Table 2 lists treatment emergent signs and symptoms that were reported in at least $2 \%$ of patients in treated may differ. Table 2 lists treatment emergent signs and symptoms that were reported in at least $2 \%$ of patients in
placebo-controlled trials who received ARICEPT ${ }^{\oplus}$ and for which the rate of occurrence was greater for ARICEPT ${ }^{\circledR}$ assigned than placebo assigned patients. In general, adverse events occurred more frequently in female patients and with advancing
Table 2. Adverse Events Reported in Controlled Clinical Trials in at Least $2 \%$ of Patients Receiving ARICEPT and at
Higher Frequency Than Placebo-treated Patients

\begin{tabular}{|c|c|c|}
\hline Body System/Adverse Event & $\begin{array}{l}\text { Placebo } \\
(\mathrm{n}=355)\end{array}$ & $\begin{array}{c}\text { ARICEPT } \\
(n=747)\end{array}$ \\
\hline $\begin{array}{l}\text { Percent of Patients With Any } \\
\text { Adverse Event }\end{array}$ & 72 & 74 \\
\hline \multicolumn{3}{|l|}{ Body as a Whole } \\
\hline Headache & 9 & 10 \\
\hline Pain, Various Locations & 8 & 9 \\
\hline Accident & 6 & 7 \\
\hline Fatigue & 3 & 5 \\
\hline \multicolumn{3}{|l|}{ Cardlovascular System } \\
\hline Syncope & 1 & 2 \\
\hline \multicolumn{3}{|l|}{ Digestive System } \\
\hline Nausea & 6 & 11 \\
\hline Diarrhea & 5 & 10 \\
\hline Vomiting & 3 & 5 \\
\hline Anorexia & 2 & 4 \\
\hline \multicolumn{3}{|l|}{ Hemic and Lymphatic System } \\
\hline Ecchymosis & 3 & 4 \\
\hline \multicolumn{3}{|c|}{ Metabolic and Nutritional Systems } \\
\hline Weight Decrease & 1 & 3 \\
\hline \multicolumn{3}{|l|}{ Musculoskeletal System } \\
\hline Muscle Cramps & 2 & 6 \\
\hline Arthritis & 1 & 2 \\
\hline \multicolumn{3}{|l|}{ Nervous System } \\
\hline Insomnia & 6 & 9 \\
\hline Dizziness & 6 & 8 \\
\hline Depression & $<1$ & 3 \\
\hline Abnormal Dreams & 0 & 3 \\
\hline Somnolence & $<1$ & 2 \\
\hline \multicolumn{3}{|l|}{ Urogenital System } \\
\hline Frequent Urination & 1 & 2 \\
\hline
\end{tabular}

age. Other Adverse Events Observed During Clinical Trials ARICEPT ${ }^{\star}$ has been administered to over 1700 individuals during clinical trials worldwide. Approximately 1200 of these patients have been treated for at least 3 months and more than 1000 patients have been treated for at least 6 months. Controlled and uncontrolled trials in the United States treated for 3 months, 475 patients treated for 6 months and 116 patients treated for over 1 year. The range of patient exposure is from 1 to 1214 days. Treatment emergent signs and symptoms that occurred during 3 controlled clinical trials exp two is rom label trials in the United States were recorded as adverse events by the clinical investigators using terminology of their own choosing. To lerminology of their own choosing. To provide an overall estimate of the proportion of individuals having similar types of and event frequencies were calculated across all studies. These categories are used in the listing below. The frequencies represent the proportion of 900 patients from these trials who experienced that event while receiving ARICEPT ${ }^{3}$. Al adverse events occurring at least twice are included, except for those al ready listed in Tables 1 or 2, COSTART terms too general to be informative, or events less likely to be drug caused. Events are classified by body system and listed using the following definitions: frequent adverse events - those occurring in at least 1/100 patients; infrequent adverse eventsthose occurring in 1/100 to 1/1000 patients. These adverse events are not necessarily related to ARICEPT treatment and additional adverse events were seen in studies conducted outside the United States. Body as a Whole: Frequent: influenza, ches chest pain, toothache; Intrequent: fever, edema face, periorbital edema, hernia hiatal, abscess, cellulitis, chills, generalized coldness, head fullness, listlessness. Cardiovascular System: Frequent: hypertension, vasodilation, atrial fibrillation, hot flashes, hypotension; Infrequent: angina pectoris, postural hypotension, myocardial infarction, AV block (first degree),
congestive heart failure, arteritis, bradycardia, peripheral vascular disease, supraventricular tachycardia, deep vein thrombosis. Digestive System: Frequent: fecal incontinence, gastrointestinal bleeding, bloating, epigastric pain Infrequent: eructation, gingivitis, increased appetite, flatulence, periodontal abscess, cholelithiasis, diverticulitis, drooling, dry mouth, fever sore, gastritis, irritable colon, tongue edema, epigastric distress, gastroenteritis, increased transaminases, hemorrhoids, ileus, increased thirst, jaundice, melena, polydypsia, duodenal ulcer, stomach ulcer thrombocythemia, thrombocytopenia, eosinophilia, erythrocytopenia. Metabolic and Nutritional Disorders: Frequent: dehydration; Infrequent: gout, hypokalemia, increased creatine kinase, hyperglycemia, weight increase. Frequent: dehydration; Infrequent: gout, hypokalemia, increased creatine kinase, hyperglycemia, weight increase,
increased lactate dehydrogenase. Musculoskeletal System: Frequent: bone fracture; Infrequent: muscle weakness, increased lactate dehydrogenase. Musculoskeletal System: Frequent: bone fracture; infrequent: muscle weakness, muscle fasciculation. Nervous System: Frequent: delusions, tremor, irritability, paresthesia, aggression, vertigo, ataxia,
increased libido, restlessness, abnormal crying, nervousness, aphasia; Infrequent: cerebrovascular accident, intracranial hemorrhage, transient ischemic attack, emotional lability, neuralgia, coldness (localized), muscle spasm, dysphoria, gai abnormality, hypertonia, hypokinesia, neurodermatitis, numbness (localized), paranoia, dysarthria, dysphasia, hostility, decreased libido, melancholia, emotional withdrawal, nystagmus, pacing. Respiratory System: Frequent: dyspnea sore throat, bronchitis; Infrequent: epistaxis, postnasal drip, pneumonia, hyperventilation, pulmonary congestion pruritus; diaphoresis, urticaria; Infrequent:-dermatitis, erythema, skin discoloration, hyperkeratosis alopecia, fungal dermatitis, herpes zoster, hirsutism, skin striae, night sweats, skin ulcer. Special Senses: Frequent: cataract, eye irritation, vision blurred; Infrequent: dry eyes, glaucoma earache tinnitus, blepharitis, decreased hearing, retinal irritation, vision blurred; Infrequent: dry eyes, glaucoma, earache, tinnitus, blepharitis, decreased hearing, retinal eyes. Urogenital System: Frequent: urinary incontinence, nocturia; Infrequent: dysuria, hematuria, urinary urgency, metrorrhagia, cystitis, enuresis, prostate hypertrophy, pyelonephritis, inability to empty bladder, breast fibroadenosis, fibrocystic breast, mastitis, pyuria, renal failure, vaginitis. Postintroduction Reports Voluntary reports of adverse events temporally associated with ARICEPT that have been received since market introduction that are not listed above and that there is inadequate data to determine the causal relationship with the drug include the following: abdominal pain agitation, cholecystitis, confusion, convulsions, hallucinations, heart block, hemolytic anemia, hyponatremia, pancreatitis, and rash. OVERDOSAGE Because strategies for the management of overdose are continually evolving, it is advisable to contact a Poison Control Center to determine the latest recommendations for the management of an overdose of any drug. As in any case of overdose, general supportive measures should be utilized Overdosage with cholinesterase inhibitors can result in cholinergic crisis characterized by severe nausea utilized. Overdosage with cholinesterase inhibitors can result in cholinergic crisis characterized by severe nausea, muscle weakness is a possibility and may result in death if respiratory muscles are involved. Tertiary anticholinergics such as atropine may be used as an antidote for ARICEPT ${ }^{\oplus}$ overdosage. Intravenous atropine sulfate titrated to effect is recommended: an initial dose of 1.0 to $2.0 \mathrm{mg}$ IV with subsequent doses based upon clinical response. Atypical responses in blood pressure and heart rate have been reported with other cholinomimetics when co-administered with quaternary anticholinergics such as glycopyrrolate. It is not known whether ARICEPT' and/or its metabolites can be removed by dialysis (hemodialysis, peritoneal dialysis, or hemofiltration). Dose-related signs of toxicity in animals included reduced spontaneous movement, prone position, staggering gait, lacrimation, clonic convulsions, depressed respiration, dosages of ARICEPT ${ }^{\circledR}$ shown to be effective in controlled clinical trials are $5 \mathrm{mg}$ and $10 \mathrm{mg}$ administered once per day. controlled clinical trials indicate that the $10 \mathrm{mg}$ dose, with a one week titration, is likely to be associated with a higher Controlled clinical trials indicate that the $10 \mathrm{mg}$ dose, with a one week titration, is likely to be associated with a higher incidence of cholinergic adverse events than the $5 \mathrm{mg}$ dose. Because steady state is not achieved for 15 days and because the contemplated until patients have been on a daily dose of $5 \mathrm{mg}$ for 4 to 6 weeks. Whether or not to employ a dose of $10 \mathrm{mg}$ is a matter of prescriber and patient preference. ARICEPT should be taken in the evening, just prior to retiring, and may be taken with or without food.

Revised September, 1998

Eisai Inc.
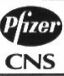
Pfizer U.S. Pharmaceutical 


\section{CNS SPECTRUMS}

The International Journal of Neuropsychiatric Medicine

\section{EDITOR}

Eric Hollander, MD

Mount Sinai School of Medicine

New York, NY

\section{INTERNATIONAL EDITOR}

Joseph Zohar, MD

Chaim Sheba Medical Center

Tel Aviv, Israel

\section{ASSOCIATE INTERNATIONAL EDITOR}

Donatella Marazziti, MD

University of Pisa

Pisa, Italy

\section{EDITORIAL DIRECTOR}

James La Rossa Jr.

\section{BOARD OF ADVISORS}

Margaret Altemus, MD

Cornell University Medical Center

New York, NY

Mitchell F. Brin, MD

Mount Sinai School of Medicine

New York, NY

John Caronna, MD

New York Hospital-Cornell

Medical Center, New York, NY

Dennis S. Charney, MD

Yale University

New Haven, CT

Emil F. Coccaro, MD

University of Chicago Medical Center

Chicago, IL

Jeffrey L. Cummings, MD

University of California

Los Angeles, CA
Dwight L. Evans, MD

University of Pennsylvania

Philadelphia, PA

Mark George, MD

Medical University of South Carolina Charleston, SC

Jack Gorman, MD

College of Physicians and

Surgeons, Columbia University

New York, NY

Thomas R. Insel, MD

Yerkes Primate Labs

Emory University School of Medicine Atlanta, GA

Lorrin M. Koran, MD

Stanford University Medical School

Stanford, CA

Herbert Y. Meltzer, MD

Vanderbilt University Medical Center Nashville, TN

Stuart A. Montgomery, MD

St. Mary's Hospital Medical School

London, United Kingdom

Dennis L. Murphy, MD

National Institute of Mental Health Bethesda, MD

Charles B. Nemeroff, MD, PhD

Emory University School of Medicine Atlanta, GA

Humberto Nicolini, MD, PhD

Instituto Mexicano de Psiquiatria Mexico

Katharine Phillips, MD

Brown University

Providence, RI
Harold A. Pincus, MD

American Psychiatric Association

Washington, DC

Stanley I. Rapoport, MD

National Institute of Mental Health Bethesda, MD

Scott L. Rauch, MD

Massachusetts General Hospital

Charlestown, MA

Alan Schatzberg, MD

Stanford University Medical School Stanford, CA

Dan J. Stein, MB

University of Stellenbosch

Tygerberg, South Africa

Norman Sussman, MD

New York University Medical School New York, NY

Neal R. Swerdlow, MD, PhD

University of California, San Diego

La Jolla, CA

Michael R. Trimble, MD

National Hospital for Neurology and Neurosurgery

London, United Kingdom

H. M. van Praag, MD

University of Maastricht

Maastricht, The Netherlands

Herman G.M. Westenberg, MD

University Hospital Utrecht

Utrecht, The Netherlands

Richard Wyatt, MD

National Institute of Mental Health Bethesda, MD

Stuart Yudofsky, MD

Baylor College of Medicine

Houston, TX

\section{MBL COMMUNICATIONS}

\section{CEO \& PUBLISHER}

James La Rossa Jr.

\section{PRESIDENT \&}

\section{ASSOCIATE PUBLISHER}

Darren L. Brodeur

MANAGING EDITOR

Claire R. Roberts

ASSOCIATE EDITORIAL DIRECTOR/
ACQUISITIONS EDITOR
Genevieve Romano
SENIOR EDITORS
Jenny R. Green
Steven Ovadia

\section{SPECIAL PROJECTS EDITOR}

Imre Balanli

PUBLISHING ASSOCIATE

Jesse D. Soll
NATIONAL ACCOUNTS

MANAGER-

EMERGING MARKETS

Paul McDaniel

\section{ASSISTANT}

ACQUISITIONS EDITORS

Kathleen Byrne

Dena Panteleakis

EDITORIAL ASSISTANTS

Jill Bazar

Janeen Labbe

Keith Papa

Joshua Ubaldi

ART DIRECTOR

Anthony J. Korsak

\section{ASSISTANT ART DIRECTOR}

Benjamin Balcomb

\section{COPY EDITORS}

Lauren Cerruto

Michelle Cervone, MD

John Martino

ADMINISTRATIVE ASSISTANT

Claudette Crawford

CONTROLLER

Richard Cortez

CORPORATION COUNSEL

Kevin F. Saer, Esq.

Davis, Wright, \& Tremaine, LLP

OF COUNSEL

Susan G. La Rossa, Esq.

Putney, Twombly, Hali \& Hirson 


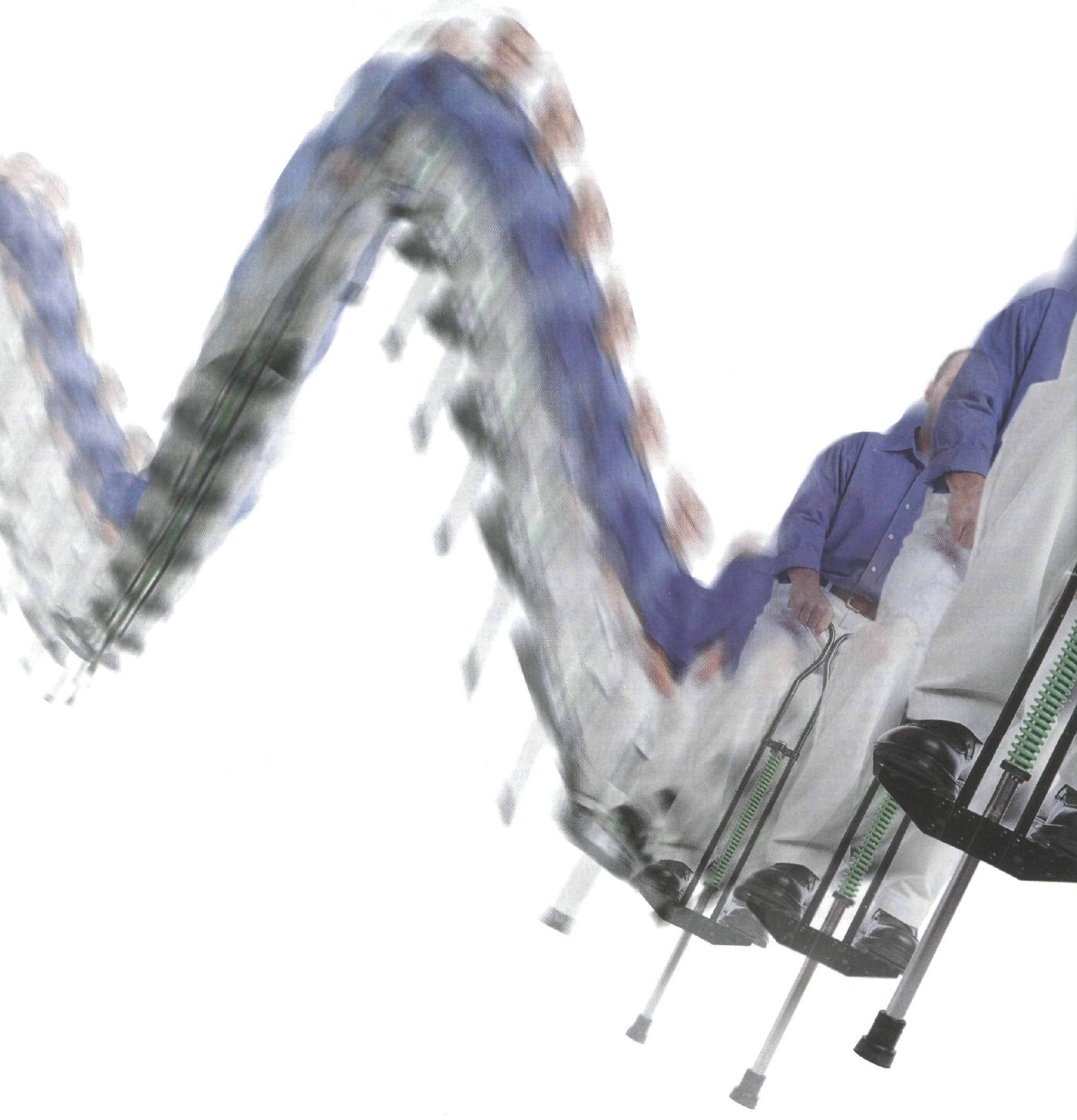

Why expose your patients to the "ups and downs" of traditional carbamazepine therapy?

Peak-to-trough fluctuations in patients receiving immediate-release carbamazepine three times daily can be as great as 2.5 fold' 


\section{Switch to Carbatrol ${ }^{\circledR}$-Second-generation delivery system design that targets the limitations of conventional carbamazepine $e^{1-6}$}

Bioequivalent to immediate-release carbamazepine dosed rigidly $\mathrm{Q}^{3} \mathrm{~h}^{3}$

- Peak-to-trough fluctuations are not compromised ${ }^{3,4}$

- Smooth, consistent plasma concentrations $s^{3,4}$

- Extensive drug dispersion, dissolution, and absorption ${ }^{2}$

- Predictable bioavailability

- BID dosing ${ }^{6}$

- No generic equivalent ${ }^{2}$

Absence seizures (petit mal) do not appear to be controlled by carbamazepine. The most frequently reported adverse events (particularly during the initial phases of therapy) are dizziness, drowsiness, unsteadiness, nausea, and vomiting. Adverse events can be minimized by initiating therapy at the lowest possible effective dose.

References: 1. Jensen PK, Moller A, Gram L, Jenson NO, Dam M. Pharmacokinetic comparison of two carbamazepine slow-release formulations. Acta Neuro/ Scand. 1990;82:135-137. 2. Data on file, Shire Richwood Inc. 3. Garnett WR, Levy B, McLean AM, et al. Pharmacokinetic evaluation of twice-daily extended-release carbamazepine (CBZ) and four-times-daily immediate-release $C B Z$ in patients with epilepsy. Epilepsia.

1998;39(3):274-279. 4. Stevens RE, Limsakun T, Evans G, Mason DH. Controlled, multidose, pharmacokinetic evaluation of two extended-release carbamazepine formulations (Carbatrol ${ }^{\circ}$ and Tegretol-XR'). J Pharm Sci. 1998:87(12):1531-1534. 5. Mahmood I, Chamberlin N. A limited sampling method for the estimation of AUC and $C_{\max }$ of carbamazepine and carbamazepine epoxide following a single and multiple dose of a sustainedrelease product. $\mathrm{Br}$ / Clin Pharmacol. 1998;45:241-246. 6. Carbatrol package insert, Shire Richwood Inc.

Please see brief summary of prescribing information on adjacent pages. Carbatrol is a registered trademark of Shire Richwood Inc.

\section{ss,}




\section{CARBATROL ${ }^{\circledR}$}

-release capsules)

$200 \mathrm{mg}$ and $300 \mathrm{mg}$

Brief Summary Prescribing information

WARNING

APLASTIC ANEMIA AND AGRANULOCYTOSIS HAVE BEEN REPORTED IN ASSOCIATION WITH THE USE OF CARBAMAZEPINE. DATA FROM A POPULATION-BASED CASE-CONTROL STUDY DEMONSTRATE THAT THE
RISK OF DEVELOPING THESE REACTIONS IS 5-8 TIMES GREATER THAN IN THE GENERAL POPULATION. HOWEVER, THE OVERALL RISK OF THESE REACTIONS IN THE UNTREATED GENERAL POPULATION IS LOW. APPROXIMATELY SIX PATIENTS PER ONE MILLION POPULATION PER YEAR FOR AGRANULOCYTOSIS AND TWO PATIENTS PER ONE MILLION POPULATION PER YEAR FOR APLASTIC ANEMIA.

ALTHOUGH REPORTS OF TRANSIENT OR PERSISTENT DECREASED PLATELET OR WHITE BLOOD CELL
COUNTS ARE NOT UNCOMMON IN ASSOCIATION WITH THE USE OF CARBAMAZEPINE, DATA ARE NOT AVAILABLE TO ESTIMATE ACCURATELY THEIR INCIDENCE OR OUTCOME. HOWEVER, THE VAST MAJORITY OF THE CASES OF LEUKOPENIA HAVE NOT PROGRESSED TO THE MORE SERIOUS CONDITIONS OF APLASTIC ANEMIA OR AGRANULOCYTOSIS

BECAUSE OF THE VERY LOW INCIDENCE OF AGRANULOCYTOSIS AND APLASTIC ANEMIA, THE VAST CARBAMAZEPINE ARE UNLIKELY TO SIGNAL THEGES OBSERVED IN MONITORING OF PATIENTS ON COMPLETE PRETREATMENT HEMATOLOGICAL TESTING SHOULD BE OBTAINED AS A BASELINE. IF A PATIENT IN THE COURSE OF TREATMENT EXHIBITS LOW OR DECREASED WHITE BLOOD CELL OR PLATELET COUNTS, THE PATIENT SHOULD BE MONITORED CLOSELY. DISCONTINUATION OF THE DRUG SHOULD BE COUNTS, THE PATIENT SHOULD BE MONITORED CLOSELY. DISCONTINUATION OF THE DRUG
CONSIDERED IF ANY EVIDENCE OF SIGNIFICANT BONE MARROW DEPRESSION DEVELOPS.

Before prescribing Carbatrol, the physician should be thoroughly familiar with the details of the full prescribin information, particularly regarding use with other drugs, especially those which accentuate toxicity potential. INDICATIONS AND USAGE

Epilepsy

Carbatrol $^{*}$ is indicated for use as an anticonvulsant drug. Evidence supporting efficacy of carbamazepine as an Pastive drug-controlled studies that enrolled patients with the following seizure types: Partial seizures with complex symptomatology (psychomotor, temporal lobe). Patients with these seizures appear to show greater improvements than those with other types.

Generalized tonic-clonic seizures (grand mal)

Mixed seizure patterns which include the above, or other partial or generalized seizures. Absence Trigeminal Neuralgia

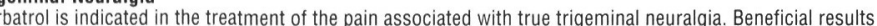
have also been reported in glossopharyngeal neuralgia. This drug is not a simple analgesic and should not be used for the relief of

not be used in patients with a history of previous bone marrow depression, hypersensitivity to the drug, or known sensitivity to any of the tricyclic compounds, such as amitriptyline, desipramine, imipramine, protriptyline and nortriptyline. Likewise, on theoretical grounds its use with
monoamine oxidase inhibitors is not recommended. Before administration of carbamazepine, MAO inhibitors should be discontinued for a minimum of 14 days, or longer if the clinical situation permits.

\section{WARNINGS}

Usage in Pregnancy

Carbamazepine can cause fetal harm when administered to a pregnant woman.

Epidemiological data suggest that there may be an association between the use of carbamazepine during pregnancy and congenital malformations, including spina bifida. The prescribing physician will wish to weigh the penefits of therapy against the risks in treating or counseling women of childbearing potential. If this drug is used during pregnancy, or if the patient becomes pregnant while taking this drug, the patient should be apprised of the potential hazard to the fetus. Retrospective case reviews suggest that, compared with monotherapy, there may be a higher prevalence of teratogenic effects associated with the use of anticonvulsants in combination therapy. humans, transplacental passage of carbamazepine is rapid (30-60 minutes), and the drug is accumulated in the fetal tissues, with higher levels found in liver and kidney than in brain and lung.

Carbamazepine has been shown to have adverse effects in reproduction studies in rats when given orally in dosages $10-25$ times the maximum human daily dosage (MHDD) of $1200 \mathrm{mg}$ on a mg/kg basis or $1.5-4$ times
the MHDD on a mg/m² basis. In rat teratology studies, 2 of 135 offspring showed kinked ribs at $250 \mathrm{mg} / \mathrm{kg}$ and 4 of 119 offspring at $650 \mathrm{mg} / \mathrm{kg}$ showed other anomalies (cleft palate, 1; talipes, 1 ; anophthalmos, 2). reproduction studies in rats, nursing offspring demonstrated a lack of weight gain and an unkempt appearance at a maternal dosage level of $200 \mathrm{mg} / \mathrm{kg}$. Antiepileptic drugs should not be discontinued abruptly in patients status epilepticus with attendant hypoxia and threat to life. In individual cases where the severity and frequency of the seizure disorder are such that removal of medication does not pose a serious threat to the patient discontinuation of the drug may be considered prior to and during pregnancy, although it cannot be said with any confidence that even minor seizures do not pose some hazard to the developing embryo or fetus. Tests to detect defects using current accepted procedures should be considered a part of routine prenatal care in childbearing women receiving carbamazepine.

\section{Genera}

Patients with a history of adverse hematologic reaction to any drug may be particularly at risk

Severe dermatologic reactions, including toxic epidermal necrolysis (Lyell's syndrome) and Stevens-Johnson syndrome have been reported with carbamazepine. These reactions have been extremely rare. However, a few atalities have been reported. Carbamazepine has shown mild anticholinergic activity; therefore, patients with increased intraocular pressure should be closely observed during therapy. Because of the relationship of the drug to other tricyclic compounds, the possibilit

\section{PRECAUTIONS}

General

Before initiating therapy, a detailed history and physical examination should be made.

Carbamazepine should be used with caution in patients with a mixed seizure disorder that includes atypica absence seizures, since in these patients carbamazepine has been associated with increased frequency of generalized convulsions (see INDICATIONS AND USAGE). Therapy should be prescribed only after critical benefito-risk appraisal in patients with a history of cardiac, hepatic, or renal damage; adverse hematologic reaction to other drugs; or interrupted cours

\section{Information for Patients}

Patients should be made aware of the early toxic signs and symptoms of a potential hematologic problem, such
as fever, sore throat, rash, ulcers in the mouth, easy bruising, petechial or purpuric hemorrhage, and should b advised to report to the physician immediately if any such signs or symptoms appear.

Since dizziness and drowsiness may occur, patients should be cautioned about the hazards of operating machinery or automobiles or engaging in other potentially dangerous tasks.

If necessary, the Carbatrol capsules can be opened and the contents sprinkled over food, such as a teaspoon of Laboratory Tests

Complete pretreatment blood counts, including platelets and possibly reticulocytes and serum iron, shoul be obtained as a baseline. If a patient in the course of treatment exhibits low or decreased white blood cell or platelet counts, the patient should be monitored closely. Discontinuation of the drug should be considered if any evidence of significant bone marrow depression develops.

Baseline and periodic evaluations of liver function, particularly in patients with a history of liver disease, must be performed during treatment with this drug since liver damage may occur. The drug should b discontinued immediately in cases of aggravated liver dysfunction or active liver disease.

Baseline and periodic eye examinations, including slit-lamp, funduscopy, and tonomet
since many phenothiazines and related drugs have been shown to cause eye changes.

Baseline and periodic complete urinalysis and BUN determinations are recommended for patients treated with this agent because of observed renal dysfunction.

Monitoring of blood levels (see CLINICAL PHARMACOLOGY) has increased the efficacy and safety of frequency and for verification of compliance. In addition, measurement of drug serum levels may aid in determining the cause of toxicity when more than one medication is being used.

Thyroid function tests have been reported to show decreased values with carbamazepine administered alone Hyponatremia has been reported in association with carbamazepine use, either alone or in combination with other drugs. Interference with some pregnancy tests has been reported.

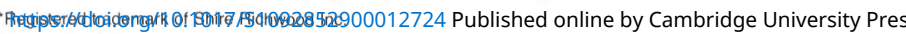

rug Interactions

limited to the following:

\section{Agents that may affect carbamazepine plasma levels:}

CYP 3 A4 inhibitors inhibit carbamazepine metabolism and can thus increase plasma carbamazepine levels.

rugs that have been shown, or would be expected, to increase plasma carbamazepine levels include:

cimetidine, danazol, diltiazem, macrolides, erythromycin, troleandomycin, clarithromycin, fluoxetine, loratadine

terfenadine, isoniazid, niacinamide, nicotinamide, propoxyphene, ketoconazole, itraconazole, verapamil, valproate. CYP $3 \mathrm{~A} 4$ inducers can increase the rate of carbamazepine metabolism and can thus decrease plasma levels include:

Efect of carbamazepine on plasma levels of concomitant agents:

Carbatrol increases levels of clomipramine $\mathrm{HCL}$, phenytoin and primidone.

Carbatrol induces hepatic CYP activity. Carbatrol causes, or would be expected to cause decreased levels of

the following:

acetaminophen, alprazolam, clonazepam, clozapine, dicumarol, doxycycline, ethosuximide, haloperido

methsuximide, oral contraceptives, phensuximide, phenytoin, theophylline, valproate, warfarin.

The doses of these drugs may therefore have to be increased when carbamazepine is added to the therapeutic regimen. Concomitant administration of carbamazepine and lithium may increase the risk of neurotoxic side effects. Alterations of thyroid function have been reported in combination therapy with other anticonvulsant medications. Breakthrough bleeding has been reported among patients receiving concomitant ora contraceptives and their reliability may be adversely affected.

Carcinogenesis, Mutagenesis, Impairment of Fertility

Administration of carbamazepine to Sprague-Dawley rats for two years in the diet at doses of 25, 75, and 250 $\mathrm{mg} / \mathrm{kg} /$ day (low dose approximately 0.2 times the maximum human daily dose of $1200 \mathrm{mg}$ on a $\mathrm{mg} / \mathrm{m}^{2}$ basis), resulted in a dose-related increase in the incide
interstitial cell adenomas in the testes of males.

interstitial cell adenomas in the testes of males.
Carbamazepine must, therefore, be considered to be carcinogenic in Sprague-Dawley rats. Bacterial and mammalian mutagenicity studies using carbamazepine produced negative results. The significance of these findings relative to the use of carbamazepine in humans is, at present, unknown.

Usage in Pregnancy

Labor and Delivery

The effect of carbam

\section{Nursing Mothers}

Carbamazepine and its epoxide metabolite are transferred to breast milk and during lactation. The

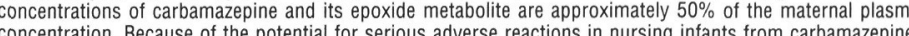
a decision should be made whether to discontinue nursing or to discontinue the drug, taking into account the importance of the drug to the mother.

\section{Pediatric Use}

Substantial evidence of carbamazepine effectiveness for use in the management of children with epilepsy (see studies in several in vitro systems which support the conclusion that (1) the pathogenic mechanism underlying seizure propagation are essentially identical in adults and children, and (2) the mechanism of action of carbamazepine in treating seizures is essentially identical in adults and children. Taken as a whole, this information supports a conclusion that the generally acceptable therapeutic range of total carbamazepine in plasma (i.e., $4-12 \mu \mathrm{g} / \mathrm{mL}$ ) is the same in children and adults. The evidence assembled was primarily obtained rom short-term use of carbamazepine. The safety of carbamazepine in children has been systematically studied up to

\section{Geriatric Use}

\section{Adverse Reactions}

General: If adverse reactions are of such severity that the drug must be discontinued, the physician must be aware that abrupt discontinuation of any anticonvulsant drug in a responsive patient with epilepsy may lead to seizures or even status epilepticus with its life-threatening hazards.

The most severe adverse reactions previously observed with carbamazepi

system (see BOX WARNING), the skin, and the cardiovascular system.

The most frequently observed adverse reactions, particularly during the initial phases of therapy, are dizziness, drowsiness, unsteadiness, nausea, and vomiting. To minimize the possibility of such reactions, therapy shoul be initiated at the lowest dosage recommended.

The following additional adverse reactions were previously reported with carbamazepine:

Hemopoietic System: Aplastic anemia, agranulocytosis, pancytopenia, bone

Skin: Pruritic and erythematous rashes, urticaria, toxic epidermal necrolysis (Lyell's syndrome) (se WARNINGS), Stevens-Johnson syndrome (see WARNINGS), photosensitivity reactions, alterations in skin pigmentation, exfoliative dermatitis, erythema multiforme and nodosum, purpura, aggravation of disseminated upus erythematosus, alopecia, and diaphoresis. In certain cases, discontinuation of therapy may be necessary. solated cases of hirsutism have been reported, but a causal relationship is not clear

Cardiovascular System: Congestive heart failure, edema, aggravation of hypertension, hypotension, syncope and collapse, aggravation of coronary artery disease, arrhythmias and AV block, thrombophlebitis
thromboembolism, and adenopathy or lymphadenopathy. Some of these cardiovascular complications have thromboembolism, and adenopathy or lymphadenopathy. Some of these cardiovascular complical

Liver: Abnormalities in liver fial infarction has been associated with other tricyclic compounds.

Respiratory System: Pulmonary hypersensitivity characterized by fever, dyspnea, pneumonitis, or pneumonia. Genitourinary System: Urinary frequency, acute urinary retention, oliguria with elevated blood pressure, azotemia renal failure, and impotence. Albuminuria, glycosuria, elevated BUN, and microscopic deposits in the urine have also been reported. Testicular atrophy occurred in rats receiving carbamazepine orally from $4-52$ weeks at dosag leen reported. Testicular atrophy occurred in rats receiving carbamazepine orally from $4-52$ weeks at dosage levels of $50-400 \mathrm{mg} / \mathrm{kg} / \mathrm{day}$. Additionally, rats receiving carbamazepine in the diet for 2 years at dosage level
of 25,75 , and $250 \mathrm{mg} / \mathrm{kg} /$ day had a dose-related incidence of testicular atrophy and aspermatogenesis. I dogs, it produced a brownish discoloration, presumably a metabolite, in the urinary bladder at dosage level of $50 \mathrm{mg} / \mathrm{kg} /$ day and higher. Relevance of these findings to humans is unknown.

Nervous System: Dizziness, drowsiness, disturbances of coordination, confusion, headache, fatigue, blurred vision, visual hallucinations, transient diplopia, oculomotor disturbances, nystagmus, speech disturbances, abnormal involuntary movements, peripheral neuritis and paresthesias, depression with agitation, talkativeness, tinnitus, and hyperacusis.

There have been reports of associated paralysis and other symptoms of cerebral arterial insufficiency, but the exact relationship of these reactions to the drug has not been established.

Isolated cases of neuroleptic malignant syndrome have been reported with concomitant use of psychotropic drugs. Digestive System: Nausea, vomiting, gastric distress and abdominal pain, diarrhea, constipation, anorexia and dryness of the mouth and pharynx, including glossitis and stomatitis.

Eyes: Scattered punctate cortical lens opacities, as well as conjunctivitis, have been reported. Although a direct causa relationship has not been established, many phenothiazines and related drugs have been shown to cause eye changes. Musculoskeletal System: Aching joints and muscles, and leg cramps.

Metabolism: Fever and chills, inappropriate antidiuretic hormone (ADH) secretion syndrome has been reported. Cases of frank water intoxication, with decreased serum sodium (hyponatremia) and confusion have of plasma calcium have been reported.

Other: Isolated cases of a lupus erythematosus-like syndrome have been reported. There have been occasional reports of elevated levels of cholesterol, HDL cholesterol, and triglycerides in patients taking anticonvulsants. A case of aseptic meningitis, accompanied by myoclonus and peripheral eosinophilia, has been reported in a patient taking carbamazepine in combination with other medications. The patient was

\section{$\mathbf{R}_{\mathbf{X}}$ only.}

700421 (rev. 8/98)

Manufactured fo

Shire Richwood Inc.

Florence, KY 41042
$1.800-536-7878$ 


\section{CNS Digest \\ In the Journal of February 2000}

\section{THE BACKLASH OF WITHDRAWAL: A SENSITIVE MATTER \\ 22-32}

"A disturbing and controversial issue surrounding the treatment of AW is that nonpharmacologic detoxification may lead to alcohol-induced neurotoxicity. Studies have shown that during AW there is an increase in excitatory neurotransmission and corticosteroid activity, both of which can be toxic to nerve cells. This may be cumulative and express itself following repeated alcohol relapses and withdrawals in the form of increased neuronal sensitization, or $\mathrm{AW}$-induced kindling. Kindling refers to the process by which repeated, subthreshold electrical or pharmacologic stimulation of certain parts of the brain can lead to behavioral changes that are more severe over time. Therefore, while AW may at times appear to be mild in its severity and self-limited in its course such that it can be treated nonpharmacologically, this approach may have long-term deleterious consequences for patients who may experience future withdrawal episodes. In fact, data suggest that moderate to severe $\mathrm{AW}$ should be treated with medication both to decrease patient discomfort and to protect against possible sensitization resulting from abrupt withdrawal of alcohol from the brain."

\section{WILLPOWER OR GENE POWER?}

\section{3-46}

"Alcohol dependence is considered a complex multidimensional disorder. While alcohol consumption has been linked to 5-HT systems, it is not assumed that all individuals who drink excessively or meet diagnostic criteria for alcohol dependence have clinically significant 5 -HT abnormalities. In Pettinati's 1996 review of 5-HT pharmacotherapy for alcohol dependence, she concluded that few of the clinical trials had targeted alcohol-dependent individuals who had clearly defined characteristics suggestive of 5-HT dysregulation. Thus, if 5-HT pharmacotherapy were given to alcoholdependent individuals with a high probability of 5-HT abnormalities, it is plausible that a more robust treatment response might be observed in selected study groups than has been reported with these agents in studies to date. For example, 5 -HT pharmacotherapies might result in greater reductions in alcohol consumption if they were prescribed for alcohol-dependent individuals who concomitantly exhibit some or all of the behaviors that are suggestive of 5-HT dysregulation, such as depression, anxiety, compulsive and/or impulsive behaviors, etc. In addition, individuals with abnormalities in neurotransmission may be genetically predisposed to alcohol dependence and may prove to be better responders to 5-HT pharmacotherapy than a more heterogeneous patient group with alcohol dependence. If it is confirmed that 5-HT pharmacotherapy works best in one or more alcohol subtypes, this could explain the inconsistency in results across the growing number of clinical trials of 5HT pharmacotherapy for reducing alcohol consumption in heterogeneous, alcohol-dependent populations."

\section{OPIOID ANTAGONISTS: THE TROJAN HORSE OF ALCOHOLISM TREATMENTS 49-57}

"Opioid antagonists may also reduce alcohol consumption by altering neuroendocrine responses to alcohol. Ethanol consumption is associated with activation of the hypothalamic-pituitary-adrenal axis and release of adrenocorticotropic hormone (ACTH), $\beta$-endorphins, and glucocorticoids. It is hypothesized that some of the positive mood effects of alcohol are mediated through this neuroendocrine mechanism. The acute administration of opioid antagonists, such as naltrexone, naloxone, and nalmefene, also activates this axis and produces increases in ACTH, cortisol, and $\beta$ endorphins. Patients receiving regular doses of naltrexone have been shown to have higher serum cortisol levels. Thus, treatment with opioid antagonists may reduce alcohol consumption by mimicking the effects of alcohol on the neuroendocrine system."

\section{ACAMPROSATE:}

\section{A RELAPSE-PREVENTION MEDICATION} 58-69

"Fourteen of 16 double-blind, placebo-controlled European trials found that alcohol-dependent outpatients treated with acamprosate had a significantly greater rate of treatment completion, longer time to first drink, higher abstinence rate, and/or longer cumulative abstinence duration compared with patients treated with placebo. Effect sizes were variable, but outcomes typically favored acamprosate over placebo in terms of primary study end points and secondary measures of GGT and/or other clinical or biological outcome measures. Additionally, high rates of medication compliance supported the acceptability of acamprosate and the tid dosing schedule in patients with alcohol dependence."

\section{MIXOLOGY: PERFECTING A COCKTAIL OF PHARMACOLOGIC AGENTS 70-76}

"Evidence points to the involvement of a number of neurochemical systems in alcoholism. These systems, including the opioid, serotonergic, and dopaminergic systems, may have a final common pathway in the mesolimbic dopaminergic system. Preclinical studies to date demonstrate that combination pharmacotherapy can be more potent and, in some cases, more specific in reducing alcohol intake than monotherapy. These results show that a mixture of low-dose naltrexone (an opioid antagonist), fluoxetine (a serotonergic compound), and TA-0910 (a dopaminergic compound) is more potent than any of these drugs individually in suppressing alcohol intake without development of tolerance in alcohol-preferring rats." 


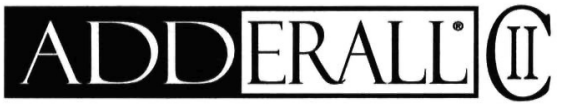

\section{ADDERALL ${ }^{\circledR}$ TABLETS}

AMPHETAMINES HAVE A HIGH POTENTIAL FOR ABUSE. ADMINISTRATION OF AMPHETAMINES FOR PROLONGED PERIODS OF TIME MAY LEAD TO DRUG DEPENDENCE AND MUST BE AVOIDED. PARTICULAR ATTENTION SHOULD BE PAID TO THE POSSIBILITY OF SUBJECTS OBTAINING AMPHETAMINES FOR NONTHERAPEUTIC USE OR DISTRIBUTION TO OTHERS, AND THE DRUGS SHOULD BE PRESCRIBED OR DISPENSED SPARINGLY.

INDICATIONS: Attention Deficit Disorder with Hyperactivity: ADDERALL is indicated as an integral part of a total treatment program which typically includes other remedial measures (psychological, educational, social) for a stabilizing effect in children with behavioral syndrome characterized by the following group of developmentally inappropriate symptoms: moderate to severe distractibility, short attention span, hyperactivity, emotional lability, and impulsivity. The diagnosis of this syndrome should not be made with finality when these symptoms are only of comparatively recent origin. Nonlocalizing (soft) neurological signs, learning disability and abnormal EEG may or may not be present, and a diagnosis of central nervous system dysfunction may or may not be warranted. In Narcolepsy: CONTRAINDICATIONS: Advanced arteriosclerosis, symptomatic cardiovascular disease, moderate to severe hypertension, hyperthyroidism, known hypersensitivity or idiosyncrasy to the sympathomimetic amines, glaucoma. Agitated states. Patients with a history of drug abuse. During or within 14 days following the administration of monoamine oxidase inhibitors (hypertensive crises may result). WARNINGS: Clinical experience suggests that in psychotic children, administration of amphetamine may exacerbate symptoms of behavior disturbance and thought disorder. Data are inadequate to determine whether chronic administration of amphetamine may be associated with growth inhibition; therefore, growth should be monitored during treatment. Usage in Nursing Mothers: Amphetamines are excreted in human milk. Mothers taking amphetamines should be advised to refrain from nursing. PRECAUTIONS: General: Caution is to be exercised in prescribing amphetamines for patients with even mild hypertension. The least amount feasible should be prescribed or dispensed at one time in order to minimize the possibility of overdosage. Information for Patients: Amphetamines may impair the ability of the patient to engage in potentially hazardous activities such as operating machinery or vehicles; the patient should therefore be cautioned accordingly. Drug Interactions: Acidifying agents Gastrointestinal acidifying agents (guanethidine, reserpine, glutamic acid $\mathrm{HCl}$, ascorbic acid, fruit juices, etc.) lower absorption of amphetamines. Urinary acidifying agents (ammonium chloride, sodium acid phosphate, etc.) Increase the concentration of the ionized species of the amphetamine molecule, thereby increasing urinary excretion. Both groups of agents lower blood levels and efficacy of amphetamines. Adrenergic blockers - Adrenergic blockers are inhibited by amphetamines. Alkalinizing agents - Gastrointestinal alkalinizing agents (sodium bicarbonate, etc.) increase absorption of amphetamines. Urinary alkalinizing agents (acetazolamide, some thiazides) increase the concentration of the nonionized species of the amphetamine molecule, thereby decreasing urinary excretion. Both groups of agents increase blood levels and therefore potentiate the actions of amphetamines. Antidepressants, tricyclic - Amphetamines may enhance the activity of tricyclic or sympathomimetic agents; d-amphetamine with desipramine or protriptyline and possibly other tricyclics cause striking and sustained increases in the concentration of $d$ amphetamine in the brain; cardiovascular effects can be potentiated. MAO inhibitors - MAO antidepressants, as well as a metabolite of furazolidone, slow amphetamine metabolism. This slowing potentiates amphetamines, increasing their effect on the release of norepinephrine and other monoamines from adrenergic nerve endings; this can cause headaches and other signs of hypertensive crisis. A variety of neurological toxic effects and malignant hyperpyrexia can occur, sometimes with fatal results. Antihistamines Amphetamines may counteract the sedative effect of antihistamines. Antihypertensives Amphetamines may antagonize the hypotensive effects of antihypertensives. Chlorpromazine - Chlorpromazine blocks dopamine and norepinephrine reuptake, thus inhibiting the central stimulant effects of amphetamines, and can be used to treat amphetamine poisoning. Ethosuximide - Amphetamines may delay intestinal absorption of ethosuximide. Haloperidol - Haloperidol blocks dopamine and norepinephrine reuptake, thus inhibiting the central stimulant effects of amphetamines. Lithium carbonate - The anorectic and stimulatory effects of amphetamines may be inhibited by lithium carbonate. Meperidine Amphetamines potentiate the analgesic effect of meperidine. Methenamine therapy Urinary excretion of amphetamines is increased, and efficacy is reduced, by acidifying agents used in methenamine therapy. Norepinephrine - Amphetamines enhance the adrenergic effect of norepinephrine. Phenobarbital - Amphetamines may delay intestinal absorption of phenobarbital; co-administration of phenobarbital may produce a synergistic anticonvulsant action. Phenytoin - Amphetamines may delay intestinal absorption of phenytoin; co-administration of phenytoin may produce a synergistic anticonvulsant action. Propoxyphene - In cases of propoxyphene overdosage, amphetamine CNS stimulation is potentiated and fatal convulsions can occur. Veratrum alkaloids - Amphetamines inhibit the hypotensive effect of veratrum alkaloids. Drug/Laboratory Test Interactions: Amphetamines can cause a significant elevation in plasma corticosteroid levels. This increase is greatest in the evening. - Amphetamines may interfere with urinary steroid determinations. Carcinogenesis/Mutagenesis: Mutagenicity studies and long-term studies in animals to determine the carcinogenic potential of amphetamine, have not been performed. Pregnancy - Teratogenic Effects: Pregnancy Category C. Amphetamine has been shown to have embryotoxic and teratogenic effects when administered to $A$ Jax mice and C57BL mice in doses approximately 41 times the maximum human dose. Embryotoxic effects were not seen in New Zealand white rabbits given the drug in doses 7 times the human dose nor in rats given 12.5 times the maximum human dose. While there are no
$5 \mathrm{mg}, 10 \mathrm{mg}, 20 \mathrm{mg} \mathrm{\&} 30 \mathrm{mg}$ TABLETS (Mixed Salts of a Single-Entity Amphetamine Product)
Dextroamphetamine Sulfate Amphetamine Sulfate Dextroamphetamine Saccharate Amphetamine Aspartate

\section{(1).BRIEF SUMMARY}

adequate and well-controlled studies in pregnant women, there has been one report of severe congenital bony deformity, tracheoesophageal fistula, and anal atresia (vater association) in a baby born to a woman who took dextroamphetamine sulfate with lovastatin during the first trimester of pregnancy. Amphetamines should be used during pregnancy only if the potential benefit justifies the potential risk to the fetus. Nonteratogenic Effects: Infants born to mothers dependent on amphetamines have an increased risk of premature delivery and low birth weight. Also, these infants may experience symptoms of withdrawal as demonstrated by dysphoria, including agitation, and significant lassitude. Pediatric Use: Long-term effects of amphetamines in children have not been well established. Amphetamines are not recommended for use in children under 3 years of age with Attention Deficit Disorder with Hyperactivity described under INDICATIONS AND USAGE. Amphetamines have been reported to exacerbate motor and phonic tics and Tourette's syndrome. Therefore, clinical evaluation for tics and Tourette's syndrome in children and their families should precede use of stimulant medications. Drug treatment is not indicated in all cases of Attention Deficit Disorder with Hyperactivity and should be considered only in light of the complete history and evaluation of the child. The decision to prescribe amphetamines should depend on the physician's assessment of the chronicity and severity of the child's symptoms and their appropriateness for his/her age. Prescription should not depend solely on the presence of one or more of the behavioral characteristics. When these symptoms are associated with acute stress reactions, treatment with amphetamines is usually not indicated. ADVERSE REACTIONS: Cardiovascular: Palpitations, tachycardia, elevation of blood pressure. There have been isolated reports of cardiomyopathy associated with chronic amphetamine use. Central Nervous System: Psychotic episodes at recommended doses (rare), overstimulation, restlessness, dizziness, insomnia, euphoria, dyskinesia, dysphoria, tremor, headache, exacerbation of motor and phonic tics and Tourette's syndrome. Gastrointestinal: Dryness of the mouth, unpleasant taste, diarrhea, constipation, other gastrointestinal disturbances. Anorexia and weight loss may occur as undesirable effects when amphetamines are used for other than the anorectic effect. Allergic: Urticaria. Endocrine: Impotence, changes in libido. DRUG ABUSE AND DEPENDENCE: Dextroamphetamine sulfate is a Schedule II controlled substance. Amphetamines have been extensively abused. Tolerance, extreme psychological dependence, and severe social disability have occurred. There are reports of patients who have increased the dosage to many times that recommended. Abrupt cessation following prolonged high dosage administration results in extreme fatigue and mental depression; changes are also noted on the sleep EEG. Manifestations of chronic intoxication with amphetamines include severe dermatoses, marked insomnia, irritability, hyperactivity, and personality changes. The most severe manifestation of chronic intoxication is psychosis, often clinically indistinguishable from schizophrenia. This is rare with oral amphetamines. OVERDOSAGE: Individual patient response to amphetamines varies widely. While toxic symptoms occasionally occur as an idiosyncrasy at doses as low as $2 \mathrm{mg}$, they are rare with doses of less than $15 \mathrm{mg} ; 30 \mathrm{mg}$ can produce severe reactions, yet doses of 400 to $500 \mathrm{mg}$ are not necessarily fatal. In rats, the oral LD50 of dextroamphetamine sulfate is $96.8 \mathrm{mg} / \mathrm{kg}$. Symptoms: Manifestations of acute overdosage with amphetamines include restlessness, tremor, hyperreflexia, rapid respiration, confusion, assaultiveness, hallucinations, panic states, hyperpyrexia and rhabdomyolysis. Fatigue and depression usually follow the central stimulation. Cardiovascular effects include arrhythmias, hypertension or hypotension and circulatory collapse. Gastrointestinal symptoms include nausea, vomiting, diarrhea, and abdominal cramps. Fatal poisoning is usually preceded by convulsions and coma. Treatment: Consult with a Certified Poison Control Center for up to date guidance and advice. Management of acute amphetamine intoxication is largely symptomatic and includes gastric lavage, administration of activated charcoal, administration of a cathartic and sedation. Experience with hemodialysis or peritoneal dialysis is inadequate to permit recommendation in this regard. Acidification of the urine increases amphetamine excretion, but is believed to increase risk of acute renal failure if myoglobinuria is present. If acute, severe hypertension complicates amphetamine overdosage, administration of intravenous phentolamine (Regitine ${ }^{\infty}$, Novartis) has been suggested. However, a gradual drop in blood pressure will usually result when sufficient sedation has been achieved. Chlorpromazine antagonizes the central stimulant effects of amphetamines and can be used to treat amphetamine intoxication. DOSAGE AND ADMINISTRATION: Regardless of indication, amphetamines should be administered at the lowest effective dosage and dosage should be individually adjusted. Late evening doses should be avoided because of the resulting insomnia. Attention Deficit Disorder with Hyperactivity: Not recommended for children under 3 years of age. In children from 3 to 5 years of age, start with $2.5 \mathrm{mg}$ daily; daily dosage may be raised in increments of $2.5 \mathrm{mg}$ at weekly intervals until optimal response is obtained. In children 6 years of age and older, start with $5 \mathrm{mg}$ once or twice daily; daily dosage may be raised in increments of $5 \mathrm{mg}$ at weekly intervals until optimal response is obtained. Only in rare cases will it be necessary to exceed a total of $40 \mathrm{mg}$ per day. Give first dose on awakening; additional doses (1 or 2) at intervals of 4 to 6 hours. Where possible, drug administration should be interrupted occasionally to determine if there is a recurrence of behavioral symptoms sufficient to require continued therapy. Narcolepsy: Usual dose $5 \mathrm{mg}$ to $60 \mathrm{mg}$ per day in divided doses, depending on the individual patient response. Narcolepsy seldom occurs in children under 12 years of age; however, when it does, dextroamphetamine sulfate may be used. The suggested initial dose for patients aged 6-12 is $5 \mathrm{mg}$ daily; daily dose may be raised in increments of $5 \mathrm{mg}$ at weekly intervals until optimal response is obtained. In patients 12 years of age and older, start with 10 $\mathrm{mg}$ daily; daily dosage may be raised in increments of $10 \mathrm{mg}$ at weekly intervals until optimal response is obtained. If bothersome adverse reactions appear (e.g., insomnia or anorexia), dosage should be reduced. Give first dose on awakening; additional doses (1 or 2) at intervals of 4 to 6 hours. Rx only. 


\section{Want Their "Undivided Attention" This School Year?}

\section{DURATION OF ACTION INCREASES WITH DOSE OF ADDERALL"}

Published study results ( $n=29)$ :

ADDERALL produced a statistically significant, dose-related increase in objective measures of behavior (number of age-appropriate math problems attempted and math problems correct) as compared to placebo

- The duration of action of ADDERALL effects on behavior were dose dependent

- No unusual or serious side effects were noted in this study

ADDERALL usage data $(n=6 \mid l)$ indicate that OVER $90 \%$ of patients can be maintained on a dosage frequency of $1-2$ times per day ${ }^{2 *}$

* Thirty-four patients receiving greater than $40 \mathrm{mg}$ per day were excluded from this analysis.

Please see references and brief summary of prescribing information on adjacent page.

ADDERALL is a registered trademark of Shire Richwood Inc.
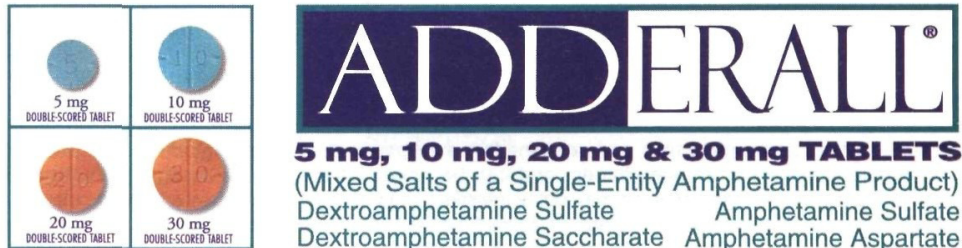

$5 \mathrm{mg}, 10 \mathrm{mg}, 20 \mathrm{mg} \& 30 \mathrm{mg}$ TABLETS

(Mixed Salts of a Single-Entity Amphetamine Product) Dextroamphetamine Sulfate Amphetamine Sulfate Dextroamphetamine Saccharate Amphetamine Aspartate

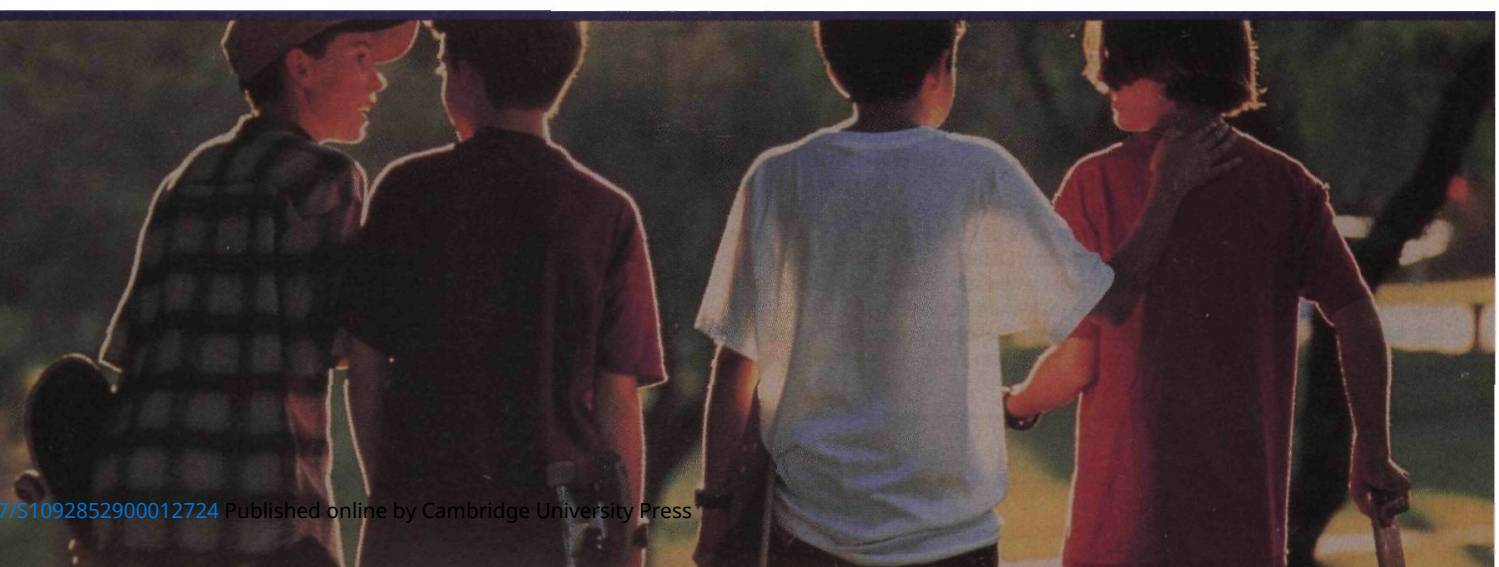




\section{Table of Contents}

Feature Articles

21 Introduction-Alcoholism: A Disorder With a Past

By Conor K. Farren, MD, PhD

22 Clinical Management of Alcohol Withdrawal

By Hugh Myrick, MD, and Raymond F. Anton, MD

33 Role of Serotonin and Serotonin-Selective

Pharmacotherapy in Alcohol Dependence

By Helen M. Pettinati, PhD, David Oslin, MD, and Kelly Decker

49 Opioid Antagonists and Alcoholism Treatment

By Robert M. Swift, MD, PhD

58 Acamprosate for the Treatment of Alcohol Dependence:

A Review of Double-Blind, Placebo-Controlled Trials

By Barbara Mason, PhD, and Raymond L. Ownby, MD, PhD

70 Combination Pharmacotherapy in Alcoholism:

A Novel Treatment Approach

By Conor K. Farren, MD, PhD, Amir H. Rezvani, PhD,

David Overstreet, PhD, and Stephanie O'Malley, PhD

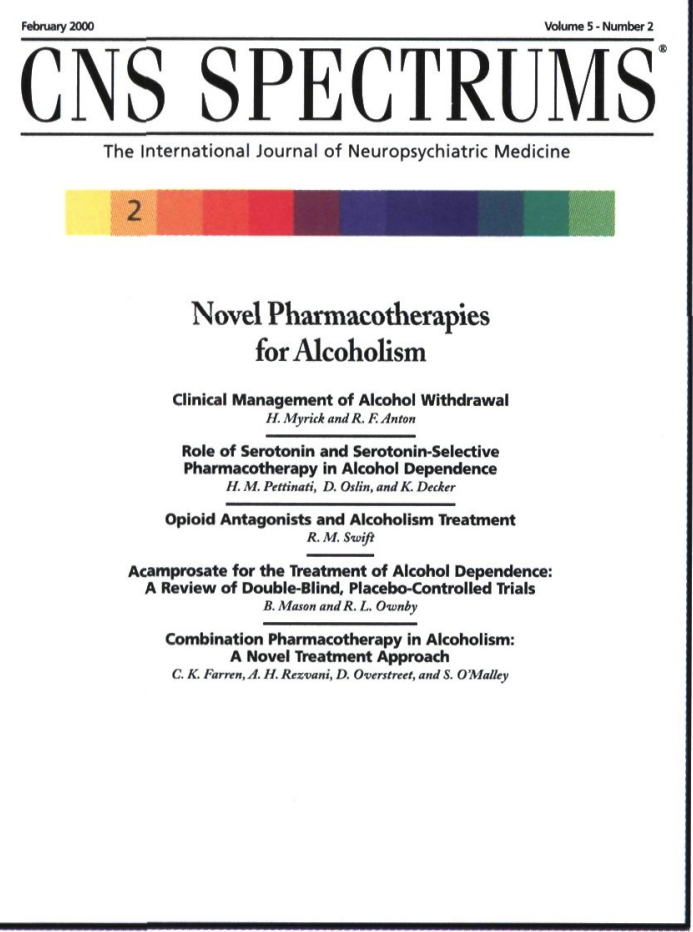

$\overline{\text { CNS SPECTRUMS }}^{\circ}$

The International Journal of

Neuropsychiatric Medicine

Volume 5 - Number 2

February 2000

CNS Spectrums is a peer review journal and is indexed in EMBASE/Excerpta Medica, DIALOG, SilverPlatter, OVID, and Lexis-Nexis. CNS Spectrums is endorsed by, and is the official journal of, the International Neuropsychiatric Association, with members in 30 countries.

\section{CNS Spectrums}

(ISSN 1092-8529)

is published monthly by

MBL Communications,

665 Broadway, Suite 805,

New York, NY 10012-2302.

Periodicals postage paid at New York, NY, and at additional mailing offices.

One year subscription rates:

domestic \$90;

foreign $\$ 145$;

in-training $\$ 50$.

For subscriptions:

Fax: 212-328-0600.

E-mail:

cns@mblcommunications.com

Postmaster:

Send address changes to

CNS Spectrums

clo PPS Medical Marketing Group

264 Passaic Ave.

Fairview, NJ 07004-2595 


\section{$\overline{\text { CNS SPECTRUMS }}$}

The International Journal of

Neuropsychiatric Medicine

Volume 5 • Number 2 February 2000

\section{Table of Contents}

Departments/Monthly Columns
10 Novel Pharmacotherapies for Alcoholism

By Eric Hollander, MD

THE NEUROLOGY OF BEHAVIOR

17 Neurobiologic Perspectives

By Michael Trimble, MD, FRCP, FRPsych

\section{CNS NEWS}

18 Briefs from the Fields of Neurology \& Neuropsychiatry

\section{CONTINUING MEDICAL EDUCATION}

79 This continuing medical education series gives the reader the opportunity to test his/her understanding and recall of clinical material presented in this issue. Approved for 3.0 credit hours in Category 1.

\section{BOOK REVIEW}

82 Social Anxiety Disorder:

The Most Human Psychiatric Disorder?

By Dan J. Stein, MB

INDICES

84 By subject and author

For editorial and advertising inquiries, please fax 212-328-0600.

Opinions and views expressed by authors are their own and do not necessarily reflect the views of the publisher, MBL Communications, or the editorial advisory board. Advertisements in CNS Spectrums are accepted on the basis of adherence to ethical medical standards, but acceptance does not imply endorsement by CNS Spectrums, or the publisher.

CNS Spectrums $®$ is a registered trademark of CNS Spectrums, LLC, New York, NY. CNS News $^{\mathrm{TM}}$ is a trademark of MBL Communications, Inc., New York, NY. 


\section{Now, a little RISPERDAL.}

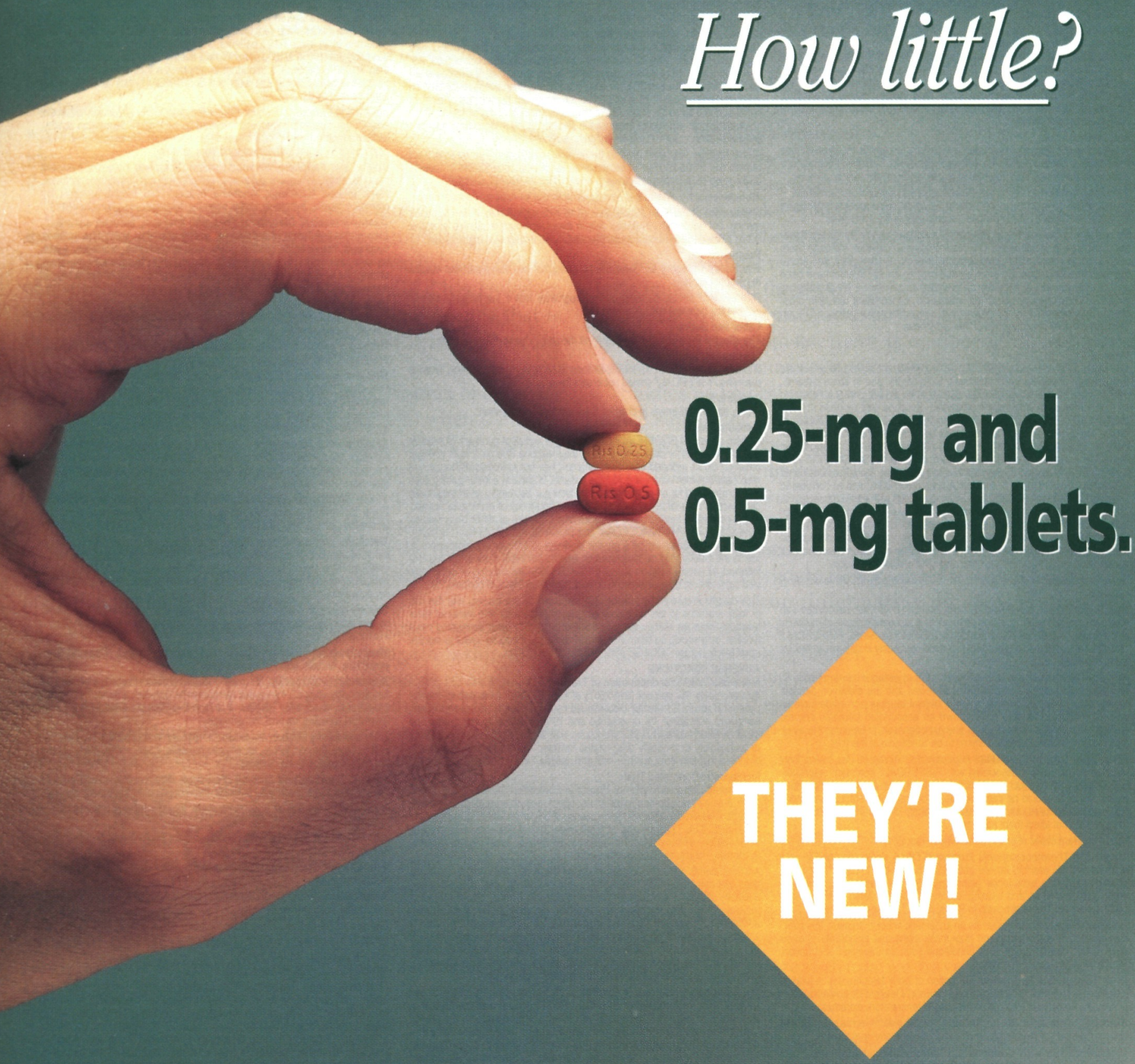

Flexibility of tablets: also $1 \mathrm{mg}, 2 \mathrm{mg}, 3 \mathrm{mg}, 4 \mathrm{mg}$ and oral solution (1 $\mathrm{mg} / \mathrm{mL})$ : in $30-\mathrm{mL}$ bottles

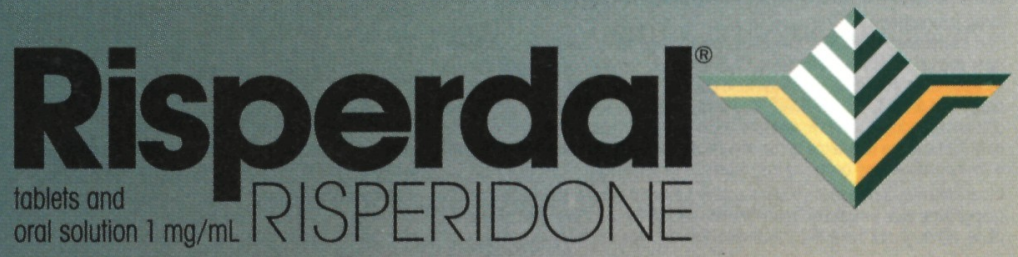




\section{Risperdal icbiets ond \\ $\sqrt{r}$}

BEFORE PRESCRIBING, PLEASE CONSULT COMPLETE PRESCRIBING INFORMATION OF WHICH THE FOLLOWING IS A BRIEF SUMMARY. INDICATIONS AND USAGE

AISPERDAL ${ }^{*}$ (risperidone) is indicated tor the management of the manifestations of psychotic disorders.

CONTRAINDICATIONS

sensitivity to the product.

WARNINGS

Neuroleptic Malignant Syndrome (NMS)

A potentially fatal symptom complex sometimes referred to as Neuroleptic Malignant Syndrome (NMS) has been reported in association with antipsychotic drugs. If a patient requires antipsychotic drug treatment after recover from NMS, the potential reintroduction of drug therapy should be caretully considered. The patient
NMS have been reported.

\section{Tardive Dyskinesia}

A syndrome of potentially irreversible, involuntary, dyskinetic movements may develop in patients treated with antipsychotic drugs. Whether antipsychotic drug products differ in their potential to cause tardive dyskinesia is unknown. If signs and symptoms of tardive dyskinesia appear in a patient on RISPERDAL: drug discontinuation should be considered. However, some patients may require
treatment with RISPERDAL

Potentlal for Proarrhythmic Effects: Risperidone and/or 9-hydroxyrisperidone appears to lengthen the QT interval in some patients, although there is no average increase in treated patients, even at $12-16 \mathrm{mg}$ day, well above the recommended dose. Other drugs that prolong the QT interval have been arrythmia. Bradycardia, electrolyte imbalance, concomitant use with othe drugs that prolong QT, or the presence of congenital prolongation in QT can
increase the risk for occurrence of this arrhythmia.

PRECAUTIONS

General

Orthostatic Hypotension: RISPERDAL ${ }^{\circledR}$ (risperidone) may induce orthostatic hypotension associated with dizziness, tachycardia, and in some patients, syncope, especially during the initial dose-titration period, probably reflectin its alpha-adrenergic antagonistic properties. Syncope was reported in $0.2 \%$
(6/2607) of RISPERDDAL treated patients in phase 2-3 studies. The risk orthostatic hypotension and syncope may be minimized by limiting the initia orthostatic hypotension and syncope may be minimized by limiting the initia
dose to $2 \mathrm{mg}$ total (either $\mathrm{QD}$ or $1 \mathrm{mg} \mathrm{BID}$ ) in normal adults and $0.5 \mathrm{mg} B I D$ in dose to $2 \mathrm{mg}$ total (either QD or $1 \mathrm{mg} \mathrm{BID}$ ) in normal adults and $0.5 \mathrm{mg}$ BID in
the elderly and patients with renal or hepatic impairment (See DOSAGE AND the elderly and patients with renal or hepatic impairment (See DOSAGE AND in patients for whom this is of concern. A dose reduction should be considered if hypotension occurs. RISPERDAL should be used with particular caution in patients with known cardiovascular disease (history of myocardial infarction or
ischemia, heart failure, or conduction abnormalities), cerebrovascular disease ischemia, heart failure, or conduction abnormalities), cerebrovascular disease,
and conditions which would predispose patients to hypotension e.g., dehydration and conditions which would predispose patients to hypotension e.g. dehydration
and hypovolemia. Clinically significant hypotension has been observed with and hypovolemia. Clinically significant hypotension has been obsen

Seizures: RISPERDAL ${ }^{\circ}$ should be used cautiously in patients with a history of seizures.

Dysphagia: Esophageal dysmotility and aspiration have been associated with antipsychotic drug use. Aspiration pneumonia is a common cause of morbidity and other antipsychotic drugs should be used cautiously in patients at risk for aspiration pneumonia.

Hyperprolactinemia: As with other drugs that antagonize dopamine $D$ receptors, risperidone elevates prolactin levels and the elevation persists during chronic administration. Neither clinical studies nor epidemiologic administration of this class of drugs and tumorigenesis in humans; the avail administration of this class of drugs and tumorigenesis in humans;

Potential for Cognitive and Motor impaiment: Somnolence was a commonly reported adverse event associated with RISPERDAL treatment, especially when ascertained by direct questioning of patients. This adverse event is dose related. Patients should be cautioned about operating hazardous machinery,
including automobiles, until they are reasonably certain that RISPERDAL therapy does not affect them adversely.

Priapism: Rare cases of priapism have been reported.

Thrombotic Thrombocytopenic Purpura (TTP): A single case of TTP was reported in a 28 year-old female patient receiving RISPERDAL in a large open premarketing experience (approximately 1300 patients). She experi-
enced jaundice, fever, and bruising, but eventually recovered after receiving enced jaundice, fever, and bruising, but eventually recovered after rece
plasmapheresis. The relationship to AISPERDAL therapy is unknown.

Antlemetic effect: Risperidone has an antiemetic effect in animals; this effect may also occur in humans, and may mask signs and symptoms of overdosage with certain drugs or of conditions such as intestinal obstruction, Reye $\mathrm{S}$ syndrome, and brain tumer.

Body Temperature Regulation: Disruption of body temperature regulation has been attributed to antipsychotic agents. Caution is advised when prescribing for patients who will be exposed to temperature extremes.

Suicide: The possibility of a suicide attempt is inherent in schizophrenia, and close supervision of high risk patients should accompany drug therapy.

Use in Patients with Concomitant IIIness: Clinical experience with RISPERDAL ${ }^{\circ}$ in patients with certain concomitant systemic illnesses is limited. Caution is advisable in using RISPERDAL
or conditions that could affect metabolism or hemodynamic responses. Because of the risks of orthostatic hypotension and QT prolongation, caution
should be observed in cardiac patients (See WARNINGS and PRECAUTIONS). Increased plasma concentrations of risperidone and 9-hydroxyrisperidone hepatic impairment. A lower starting dose should be used in such patients.

\section{Information for Patients}

Physicians are advised to consult full prescribing information to review issues Drug Interactions

The interactions of RISPERDAL ${ }^{*}$ and other drugs have not been systematically evaluated. Given the primary CNS effects of risperidone, caution should be used when RISPERDAL ${ }^{\circ}$ is taken in combination with other centrally acting drugs and alcohol. RISPERDAL may antagonize the effects of levodopa and dopamine agonists. Chronic administration of carbamazepine with risperidone may increase the clearance of risperidone. Chronic administr
with risperidone may decrease the clearance of risperidone.

Fluoxetine may increase the plasma concentration of the anti-psychotic fraction (risperidone plus 9-hydroxyrisperidone) by raising the concentration of rispendone, although not the active metabolite, 9-hydroxyrisperidone.
Drugs that Inhibit Cytochrome $P_{111}$, and Other $P_{\mathrm{e}}$ Isozymes: Risperidone is metabolized to 9 -hydroxyrisperidone by cytochrome $P_{\text {suli }}$, an enzyme tha is polymorphic in the population and that can be inhibited by a variety of psychotropic and other drugs (See CLINICAL PHARMACOLOGY). Drug interwould increase the plasma concentrations of risperidone and lower the concentrations of 9-hydroxyrisperidone. Analysis of cinical studies involving modest number of poor metabolizers $(n=70)$ does not suggest that poor and extensive metabolizers have different rates of advers
comparison of effectiveness in the two groups has been made. In vitro studies showed that drugs metabolized by other $P_{e}$ isozymes, including Orugs risperidone is a relatively weak inhibitor of cytochrome $P$ IID. There the risperidone is a relatively weak inhibitor of cytochrome $P_{w}$ ind that are metabolized by this enzymatic pathway. However, clinical data to confirm this expectation are not available.

Carcinogenesis, Mutagenesis, Impairment of Fertility

Carcinogenesis: Carcinogenicity studies were conducted in Swiss albino mice and Wistar rats. Risperidone was administered in the diet at doses of $0.63,2.5$, and $10 \mathrm{mg} / \mathrm{kg}$ for 18 months to mice and for 25 months to rats. These doses are a malen basis or 0.20 .75 and 3 times the maximum human dose (mice) or a mg/kg basis or $0.2,0.75$ and 3 times the maximum human dose (mice)
$0.4,1.5$, and 6 times the maximum human dose (rats) on a $\mathrm{mg} / \mathrm{m}^{2}$ basis. There were statistically significant increases in pituitary gland adenomas, endocrine pancreas adenomas and mammary gland adenocarcinomas.

These findings are considered to be prolactin medicated. The relevance for human risk of the findings of prolactin-mediated endocrine tumors in rodents
is unknown (See Hyperprolactinemia under PRECAUTIONS, GENERAL).

Mutagenesis: No evidence of mutagenic potential for risperidone was found. Impairment of Fertility: Risperidone ( 0.16 to $5 \mathrm{mg} / \mathrm{kg}$ ) was shown to impair mating, but not fertility, in Wistar rats in three reproductive studies at dose Pregnancy

Pregnancy Category C: There are no adequate and well-controlled studies in pregnant women.

RISPERDAL ${ }^{\circ}$ should be used during pregnancy only if the potential benefit justifies the potential risk to the fetus.

Labor and Delivery

Nursing Mothers

It is not known whether or not risperidone is excreted in human milk. Wome receiving RISPERDAL ${ }^{\circ}$ should not breast feed.

Pediatric Use

Safety and effectiveness in children have not been established.

Geriatric Use

Clinical studies of RISPERDAL ${ }^{\bullet}$ did not include sufficient numbers of patients aged 65 and over to determine whether they respond differently from younger patients. Other reported clinical experience has not identified differences in is recommended for an elderly patient, reflecting general, a lower starting dose clearance in the elderly, as well as a greater frequency of decreased hepatic renal, or cardiac function, and of concomitant disease or other drug therapy
(See CLINICAL PHARMACOLOGY and DOSAGE AND ADMINISTRATION) While elderly patients exhibit a greater tendency to orthostatic hypotension, its risk in the elderly may be minimized by limiting the initial dose to $0.5 \mathrm{mg}$ BID vital signs should be considered in patients for whom this is of concern.

This drug is known to be substantially excreted by the kidney, and the risk of toxic reactions to this drug may be greater in patients with impaired ren function, care should be taken in dose selection, and it may be useful to monito function, care should be taken in dose selection, and it may be
renal function (See DOSAGE AND ADMINISTRATION).

\section{ADVERSE REACTIONS}

\section{Associated with Discontinuation of Treatment}

Approximately $9 \%$ percent (244/2607) of RISPERDAL (risperidone)-treated patients in phase 2-3 studies discontinued treatment due to an adverse event compared with about $7 \%$ on placebo and $10 \%$ on active control drugs. The more common events $(\geq 0.3 \%)$ associated with discontinuation and considered to be possibly or probably drug-related included:
dizziness, hyperkinesia, somnolence, and nausea.

\section{Incidence in Controlled Trials}

Commonly Observed Adverse Events in Controlled Clinical Trials: In two 6- to 8-week placebo-controlled trials, spontaneously-reported, treatmentemergent adverse events with an incidence of $5 \%$ or greater in at least one of
the RISPERDAL the $\mathrm{h}$ ( somnolence, extrapyramidal symptoms,
dyspepsia, rhinitis, rash, and tachycardia.

Adverse events were also elicited in one of these two trials fi.e., in the fixeddose trial comparing RISPERDAL ${ }^{3}$ at doses of 2, 6, 10, and $16 \mathrm{mg} /$ day with placebo) utilizing a checklist for detecting adverse events, a method that is
more sensitive than spontaneous reporting. By this method, the following additional common and drug-related adverse events were present at least $5 \%$ and twice the rate of placebo: increased dream activity, increased duration of and twice the rate of placebo: increased dream activity, increased duration of bances, diarmea, weight gain, menorrhagia, diminished sexual desire, erectile bances, diarmea, weight gain, menorrhagia, diminished sexual
dystunction, ejaculatory dysfunction, and orgastic dystunction.

The following adverse events occurred at an incidence of $1 \%$ or more, an were at least as frequent among RISPERDAL treated patients treated at doses of $\leq 10 \mathrm{mg} /$ day than among placebo-treated patients in the pooled results of two 6- to 8-week controlled tnals: Psychiatric Disorders: insomnia, agitation, anxiety, somnolence, aggressive reaction. Nervous System: extrapyramidal symptoms', headache, dizziness. Gastrointestinal System: constipation, nausea, dyspepsia, vomiting, abdominal pain, saliva increased, toothache. Respiratory System: rhinitis, coughing, sinusitis, pharyngtis, dyspnea. Body as a Whole: back pain, chest pain, fever. Dermatological rash, dry skin, seborrhea. Infections: upper respiratory. Visual:
vision. Musculo-Skeletal: arthralgia. Cardiovascular: tachycardia.

Includes tremor, dystonia, hypokinesia, hypertonia, hyperkinesia, oculogyric
crisis, ataxia, abnormal gait, involuntary muscle contractions, hyporefiexia, akathisia, and extrapyramidal disorders.

\section{Dose Dependency of Adverse Events:}

Data from two fixed dose trials provided evidence of dose-relatedness for extrapyramidal symptoms associated with risperidone treatment. These sympdisturbances, orthostatic dizziness, palpitations, weight gain, erectile dysfunction ejaculatory dysfunction, orgastic dysfunction, asthenia/lassitude/increased fatiguability, and increased pigmentation.

Vital Sign Changes: RISPERDAL ${ }^{*}$ is associated with orthostatic hypotension and techycardia (See PRECAUTIONS).

Weight Changes: A statistically significantly greater incidence of weight gain for RISPERDAL $(18 \%)$ compared to placebo $(9 \%$.

Laboratory Changes: A between group comparison for 6- to 8-week placebocontrolled trials revealed no statistically significant RISPERDAL $/$ placebo

changes in routine serum chemistry, hematology, or urinalysis parameters. Similarly, there were no RISPERDAL \&/placebo differences in the incidence of discontinuations for changes in serum chemistry, hematology, or urinalysis.
However, RISPERDAL administration was associated with increases in However, RISPERDAL administration

ECG Changes: The electrocardiograms of approximately 380 patients who received RISPERDAL ${ }^{8}$ and 120 patients who received placebo in two doubleblind, placebo-controlled trials were evaluated and revealed one finding of potential concern; i.e.. 8 patients taking RISPERDAL ${ }^{*}$ whose baseline QTC interval was less than $450 \mathrm{msec}$ were observed to have QTc intervals greater than $450 \mathrm{msec}$ during treatment (See WARNINGS). Changes of this type receiving haloperidol (3/126).

Other Events Observed During the Pre-Marketing Evaluation of RISPERDAL ${ }^{\circ}$

During its premarketing assessment, multiple doses of RISPERDAL (risperione) were administered to 2607 patients in phase 2 and 3 studies and the occurring in at least 1/100 patients. Intrequent adverse events are those occurring in at least $1 / 100$ patients. Intrequent adverse events are those than $1 / 1000$ patients. It is important to emphasize that, although the events reported occurred during treatment with RISPERDAL ${ }^{3}$, they were not necessarily caused by it.)

Psychiatric Disorders: Frequent increased dream activity", diminished sexua desire", nervousness. Infrequent: impaired concentration, depression, apathy. catatonic reaction, euphoria, increased libido, amnesia. Rare: emotional lability. nightmares, delirium, withdrawal syndrome, yawning

Central and Peripheral Nervous System Disorders: Frequent: increase sleep duration". Infrequent: dysarthria, vertigo, stupor, paraesthesia, confusion. Rare: aphasia, cholinergic syndrome, hypoesthesia, tongue paralysis, leg cramps, torticollis, hypotonia, coma, migraine, hyperreflexia, choreoathetosis. Gastro-intestinal Disorders: Frequent: anorexia, reduced salivation" Infrequent: flatulence, diarrhea, increased appetite, stomatitis, melena dysphagia, hemornhoids, gastritis. Rare: fecal incontinence, eructation, gastrocholelithiasis, tongue edema, diverticulitis, gingivitis, discolored feces, Gi hemorrhage, hematemesis.

Body as a Whole/General Disorders: Frequent: fatigue. Infrequent: edema, rigors, malaise, influenza-like symptoms. Rare: pallor, enlarged abdomen, allergic reaction, ascites, sarcoidosis, flushing.

Respiratory System Disorders: Infrequent: hyperventilation, bronchospasm, pneumonia, stridor. Rare: asthma, increased sputum, aspiration.

Skin and Appendage Disorders: Frequent: increased pigmentation", photosensitivity*. Infrequent: increased sweating, acne, decreased sweating. alopecia, hyperkeratosis, pruritus, skin extoliation. Rare: bullous eruption, skin ulceration, aggravated psoriasis, furuncul

Cardiovascular Disorders: Infrequent: palpitation, hypertension, hypotension, AV block, myocardial infarction. Rare: ventricular tachycardia, angina pectoris premature atrial contractions, T wave inversions, ventricular extrasystoles, ST depression, myocarditis.

Vision Disorders: Infrequent: abnormal accommodation, xerophthalmia Rare: diplopia, eye pain, blepharitis, photopsia, photophobia, abnorma

Metabolic and Nutritional Disorders: Infrequent: hyponatremia, weigh increase, creatine phosphokinase increase, thirst, weight decrease, diabeles mellitus. Rare: decreased serum iron, cachexia, dehydration, hypokalemia hypoproteinemia

Urinary System Disorders: Frequent: polyuria/polydipsia*. Infrequent: urinary incontinence, hematuria, dysuria. Rare: urinary retention, cystitis, renal sufficiency.

Musculo-skeletal System Disorders: Infrequent: myalgia. Rare: arthrosis, synostosis, bursitis, arthritis, skeletal pain

Reproductive Disorders, Female: Frequent: menorrhagia*, orgastic dysfunction", dry vagina*. Infrequent: nonpuerperal lactation, amenorrhea, female breast pain, leukormea, mastitis, dysmen
menstrual bleeding, vaginal hemormage.

Liver and Biliary System Disorders: Infrequent increased SGOT, increased SGPT. Rare: hepatic failure, cho

Platelet, Bleeding and Clotting Disorders: Intrequent: epistaxis, purpura Pare hemorrhage, superficial phlebitis, thrombophlebitis, thrombocytopenia Hearing and Vestibular Disorders: Rare: tinnitus, hyperacusis, decreased earing.

Red Blood Cell Disorders: Intrequent: anemia, hypochromic anemia. Rare normocytic anemia.

Reproductive Disorders, Male: Frequent: erectile dysfunction". Infrequent ejaculation failure.

White Cell and Resistance Disorders: Rare: ieukocytosis, lymphadenopathy, ucopenia, Pelger-Huet anomaly.

Endocrine Disorders: Rare: gynecomastia, maie breast pain, antidiuretic ormone disorde

Special Senses: Rare: bitter taste.

"

Postintroduction Reports: Adverse events reported since market introduction which were temporally (but not necessarily causally) related to ISPERDAL ${ }^{\circ}$ therapy, include the following: anaphylactic reaction, angiodema, apnea, atrial fibrillation, cerebrovascular disorder, diabetes mellitus ggravated, including diabetic ketoacidosis, intestinal obstruction, jaundice Ther, pancrealis, Pankinson's disease aggravaled, pulmonary embolism. There have been rare reports of sudden death and/or cardiopulmonary arres has natients receiving RiSPERDAL. A causal relationship with RISPERDAL death may occur in psychotic patients whether they remain untreated or whether they are treated with other antipsychotic drugs.

DRUG ABUSE AND DEPENDENCE

Controlled Substance Class: RISPERDAL ${ }^{\circ}$ (rispenidone) is not a controlled substance.

For information on symptoms and treatment of overdosage, see full 